$1-10-2007$

\title{
A Microfabricated Involute-Foil Regenerator for Stirling Engines
}

\author{
Roy C. Tew \\ NASA Glenn Research Center \\ Mounir B. Ibrahim \\ Cleveland State University, m.ibrahim@csuohio.edu \\ Daniel Danila \\ Cleveland State University \\ Terrence W. Simon \\ University of Minnesota \\ Susan Mantell \\ University of Minnesota
}

See next page for additional authors

Follow this and additional works at: https://engagedscholarship.csuohio.edu/enme_facpub

Part of the Mechanical Engineering Commons

How does access to this work benefit you? Let us know!

\section{Recommended Citation}

Tew, Roy C.; Ibrahim, Mounir B.; Danila, Daniel; Simon, Terrence W.; Mantell, Susan; Sun, Liyong; Gedeon, David; Kelly, Kevin; McLean, Jeffrey; Wood, Gary; and Qiu, Songgang, "A Microfabricated Involute-Foil Regenerator for Stirling Engines" (2007). Mechanical Engineering Faculty Publications. 264.

https://engagedscholarship.csuohio.edu/enme_facpub/264

This Report is brought to you for free and open access by the Mechanical Engineering Department at EngagedScholarship@CSU. It has been accepted for inclusion in Mechanical Engineering Faculty Publications by an authorized administrator of EngagedScholarship@CSU. For more information, please contact library.es@csuohio.edu. 


\section{Authors}

Roy C. Tew, Mounir B. Ibrahim, Daniel Danila, Terrence W. Simon, Susan Mantell, Liyong Sun, David Gedeon, Kevin Kelly, Jeffrey McLean, Gary Wood, and Songgang Qiu 
NASA/TM-2007-214973

AIAA-2007-4739

NTA- A

$\times+.+1+$

\section{A Microfabricated Involute-Foil Regenerator for Stirling Engines}

Roy Tew

Glenn Research Center, Cleveland, Ohio

Mounir Ibrahim and Daniel Danila

Cleveland State University, Cleveland, Ohio

Terrence Simon, Susan Mantell, and Liyong Sun

University of Minnesota, Minneapolis, Minnesota

David Gedeon

Gedeon Associates, Athens, Ohio

Kevin Kelly and Jeffrey McLean

International Mezzo Technologies, Baton Rouge, Louisiana

Gary Wood

Sunpower Incorporated, Athens, Ohio

Songgang Qiu

Infinia Corporation, Kennewick, Washington 


\section{NASA STI Program . . . in Profile}

Since its founding, NASA has been dedicated to the advancement of aeronautics and space science. The NASA Scientific and Technical Information (STI) program plays a key part in helping NASA maintain this important role.

The NASA STI Program operates under the auspices of the Agency Chief Information Officer. It collects, organizes, provides for archiving, and disseminates NASA's STI. The NASA STI program provides access to the NASA Aeronautics and Space Database and its public interface, the NASA Technical Reports Server, thus providing one of the largest collections of aeronautical and space science STI in the world. Results are published in both non-NASA channels and by NASA in the NASA STI Report Series, which includes the following report types:

- TECHNICAL PUBLICATION. Reports of completed research or a major significant phase of research that present the results of NASA programs and include extensive data or theoretical analysis. Includes compilations of significant scientific and technical data and information deemed to be of continuing reference value. NASA counterpart of peer-reviewed formal professional papers but has less stringent limitations on manuscript length and extent of graphic presentations.

- TECHNICAL MEMORANDUM. Scientific and technical findings that are preliminary or of specialized interest, e.g., quick release reports, working papers, and bibliographies that contain minimal annotation. Does not contain extensive analysis.

- CONTRACTOR REPORT. Scientific and technical findings by NASA-sponsored contractors and grantees.
- CONFERENCE PUBLICATION. Collected papers from scientific and technical conferences, symposia, seminars, or other meetings sponsored or cosponsored by NASA.

- SPECIAL PUBLICATION. Scientific, technical, or historical information from NASA programs, projects, and missions, often concerned with subjects having substantial public interest.

- TECHNICAL TRANSLATION. Englishlanguage translations of foreign scientific and technical material pertinent to NASA's mission.

Specialized services also include creating custom thesauri, building customized databases, organizing and publishing research results.

For more information about the NASA STI program, see the following:

- Access the NASA STI program home page at http://www.sti.nasa.gov

- E-mail your question via the Internet to help@sti.nasa.gov

- Fax your question to the NASA STI Help Desk at 301-621-0134

- Telephone the NASA STI Help Desk at 301-621-0390

- Write to: NASA Center for AeroSpace Information (CASI) 7115 Standard Drive Hanover, MD 21076-1320 
NASA/TM-2007-214973

AIAA-2007-4739

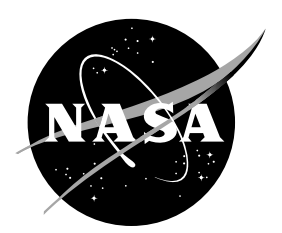

\section{A Microfabricated Involute-Foil Regenerator for Stirling Engines}

Roy Tew

Glenn Research Center, Cleveland, Ohio

Mounir Ibrahim and Daniel Danila

Cleveland State University, Cleveland, Ohio

Terrence Simon, Susan Mantell, and Liyong Sun

University of Minnesota, Minneapolis, Minnesota

David Gedeon

Gedeon Associates, Athens, Ohio

Kevin Kelly and Jeffrey McLean

International Mezzo Technologies, Baton Rouge, Louisiana

Gary Wood

Sunpower Incorporated, Athens, Ohio

Songgang Qiu

Infinia Corporation, Kennewick, Washington

Prepared for the

Fifth International Energy Conversion Engineering Conference and Exhibit (IECEC)

sponsored by the American Institute of Aeronautics and Astronautics

St. Louis, Missouri, June 25-27, 2007

National Aeronautics and

Space Administration

Glenn Research Center

Cleveland, Ohio 44135 


\section{Acknowledgments}

The work described in this paper was performed for the NASA Science Mission Directorate (SMD) and the Radioisotope Power System (RPS) Program.

Level of Review: This material has been technically reviewed by technical management.

Available from

NASA Center for Aerospace Information 7115 Standard Drive

Hanover, MD 21076-1320
National Technical Information Service 5285 Port Royal Road Springfield, VA 22161

Available electronically at http://gltrs.grc.nasa.gov 


\title{
A Microfabricated Involute-Foil Regenerator for Stirling Engines
}

\author{
Roy Tew \\ National Aeronautics and Space Administration \\ Glenn Research Center \\ Cleveland, Ohio 44135 \\ Mounir Ibrahim and Daniel Danila \\ Cleveland State University \\ Cleveland, Ohio 44115 \\ Terrence Simon, Susan Mantell, and Liyong Sun \\ University of Minnesota \\ Minneapolis, Minnesota 55455 \\ David Gedeon \\ Gedeon Associates \\ Athens, Ohio 45701 \\ Kevin Kelly and Jeffrey McLean \\ International Mezzo Technologies \\ Baton Rouge, Louisiana 70806 \\ Gary Wood \\ Sunpower Incorporated \\ Athens, Ohio 45701 \\ Songgang Qiu \\ Infinia Corporation \\ Kennewick, Washington 99336
}

\begin{abstract}
A segmented involute-foil regenerator has been designed, microfabricated and tested in an oscillatingflow rig with excellent results. During the Phase I effort, several approximations of parallel-plate regenerator geometry were chosen as potential candidates for a new microfabrication concept. Potential manufacturers and processes were surveyed. The selected concept consisted of stacked segmentedinvolute-foil disks (or annular portions of disks), originally to be microfabricated from stainless-steel via the LiGA (lithography, electroplating, and molding) process and EDM. During Phase II, re-planning of the effort led to test plans based on nickel disks, microfabricated via the LiGA process, only. A stack of nickel segmented-involute-foil disks was tested in an oscillating-flow test rig. These test results yielded a performance figure of merit (roughly the ratio of heat transfer to pressure drop) of about twice that of the 90 percent random fiber currently used in small $\sim 100 \mathrm{~W}$ Stirling space-power convertors - in the Reynolds Number range of interest (50 to 100). A Phase III effort is now underway to fabricate and test a segmented-involute-foil regenerator in a Stirling convertor. Though funding limitations prevent optimization of the Stirling engine geometry for use with this regenerator, the Sage computer code will be used to help evaluate the engine test results. Previous Sage Stirling model projections have indicated that a segmented-involute-foil regenerator is capable of improving the performance of an optimized involutefoil engine by 6 to 9 percent; it is also anticipated that such involute-foil geometries will be more reliable
\end{abstract}


and easier to manufacture with tight-tolerance characteristics, than random-fiber or wire-screen regenerators. Beyond the near-term Phase III regenerator fabrication and engine testing, other goals are (1) fabrication from a material suitable for high temperature Stirling operation (up to $850{ }^{\circ} \mathrm{C}$ for current engines; up to $1200{ }^{\circ} \mathrm{C}$ for a potential engine-cooler for a Venus mission), and (2) reduction of the cost of the fabrication process to make it more suitable for terrestrial applications of segmented involute foils. Past attempts have been made to use wrapped foils to approximate the large theoretical figures of merit projected for parallel plates. Such metal wrapped foils have never proved very successful, apparently due to the difficulties of fabricating wrapped-foils with uniform gaps and maintaining the gaps under the stress of time-varying temperature gradients during start-up and shut-down, and relatively-steady temperature gradients during normal operation. In contrast, stacks of involute-foil disks, with each disk consisting of multiple involute-foil segments held between concentric circular ribs, have relatively robust structures. The oscillating-flow rig tests of the segmented-involute-foil regenerator have demonstrated a shift in regenerator performance strongly in the direction of the theoretical performance of ideal parallelplate regenerators.

\section{Nomenclature}

$\begin{array}{ll}\text { A } & \text { wetted area, in hydraulic diameter definition } \\ \text { Darcy_f } & \text { Darcy friction factor } \\ d_{h} & \text { hydraulic diameter } \\ f & \text { friction factor } \\ N_{k} & \text { "thermal-dispersion-conduction enhancement" or "conductivity ratio" defined as the } \\ & \text { fluid-effective-axial conductivity divided by the fluid-molecular conductivity } \\ N_{u}, N u_{-} m & \text { Nusselt number, mean Nusselt number } \\ P & \text { wetted perimeter, in hydraulic diameter definition } \\ P e & \text { Peclet number ( = Reynolds number x Prandtl number) } \\ P_{r} & \text { Prandtl number } \\ R e & \text { Reynolds number } \\ U x, U y, U z & \text { Maximum displacements in } x, y, \text { and z directions, respectively (from FEA structural } \\ & \text { analysis) } \\ x & \text { axial distance } \\ x^{+} & x /\left(d_{h} \cdot \operatorname{Re}\right)=\text { dimensionless length used for friction-factor plots } \\ x^{*} & x /\left(d_{h} \cdot \operatorname{Re} \cdot \operatorname{Pr}\right)=\text { dimensionless length used for Nusselt number plots }\end{array}$

\section{Abbreviations}

CAD Computer Aided Design

CFD

Computational Fluid Dynamics

CSU

Cleveland State University

DOE Department of Energy

EDM Electrical Discharge Machining

FEA Finite Element Analysis

FTB Frequency Test Bed (convertor, or engine and linear alternator)

GRC Glenn Research Center

LiGA Lithographie, Galvanoformung and Abformung (the German words for lithography, electroplating and molding. X-ray lithography is used here)

LSMU Large Scale Mock Up (of involute-foils)

NASA National Aeronautics and Space Administration

NRA NASA Research Award

PMMA Polymethyl methacrylate (a clear plastic, also marketed as Acrylic, Plexiglas, Lucite, etc. Used as a photoresist in LiGA process for microfabrication of involute-foils) 
SEM

TCR

UMN
Scanning Electron Microscope

Thermal Contact Resistance

University of Minnesota

\section{Introduction}

A segmented-involute-foil regenerator has been designed, microfabricated and tested in a NASA/Sunpower oscillating-flow test rig (refs. 1 to 4) with excellent results. The work was funded via a NRA to Cleveland State University; subcontractors were the University of Minnesota, Gedeon Associates, International Mezzo Technologies, Sunpower Incorporated and Infinia Corporation.

During the Phase I effort, several approximations of parallel-plate regenerator geometry were chosen as potential candidates for a new microfabrication concept. Potential manufacturers and processes were surveyed. The selected concept consisted of stacked segmented-involute-foil disks (or annular portions of disks), originally to be microfabricated from stainless-steel via the LiGA process and EDM. However, during Phase II, difficulties with the EDM process plus re-planning of the effort due to anticipated funding shortages led to test plans based on nickel disks, microfabricated via the LiGA process, only.

The resulting segmented-involute-foil disks were stacked into a canister and tested in the oscillatingflow rig. Analysis of the results yielded a performance figure of merit (roughly the ratio of heat transfer to pressure drop) of about twice that of the 90 percent random fiber currently used; this comparison is based on the Reynolds number range of interest ( $\sim 50$ to 100$)$ in the small $\sim 100 \mathrm{~W}$ Stirling space-power convertors under development by DOE, NASA and Sunpower.

A scaled-down version of the originally-planned Phase III NRA effort is now underway- to fabricate and test a nickel segmented-involute-foil regenerator in a Sunpower FTB Stirling convertor. Though funding limitations prevent optimization of the Stirling-engine geometry for use with this regenerator, the Sage (ref. 5) computer code, used in the design of Infinia and Sunpower Stirling devices, will be used to help evaluate the engine test results. Previous Sage projections indicated that an involute-foil regenerator is capable of improving the performance of an optimized involute-foil engine by 6 to 9 percent; it is also anticipated that involute-foil geometries will be more reliable and easier to manufacture with tighttolerance characteristics (e.g., porosity) than random-fiber or wire-screen regenerators. Test of this new regenerator in the non-optimized Stiring FTB convertor will not demonstrate the full performance potential of the segmented-involute-foil regenerator; but these tests will help determine if there are any decrements in performance associated with inserting the regenerator into the engine and testing it that were not revealed by the oscillating-flow rig test.

Beyond the near-term Phase III regenerator fabrication and engine testing, other needed developments are (1) fabrication from a material suitable for high-temperature Stirling operation (up to $850{ }^{\circ} \mathrm{C}$ in a current Sunpower space engine; up to $1200{ }^{\circ} \mathrm{C}$ for a potential engine-cooler for a Venus mission), and (2) reduction of the cost of the fabrication process for terrestrial applications of involute-foil regenerators.

Past attempts have been made to use wrapped foils to approximate the large theoretical figures of merit projected for stacks of parallel plates. Such metal wrapped foils have never proved very successful, apparently due to the difficulties of fabricating wrapped-foils with uniform gaps and maintaining the uniformity under the stress of time-varying temperature gradients during start-up and shut-down, and relatively-steady temperature gradients during normal operation. In contrast, stacks of segmentedinvolute-foil annuli, with each annulus consisting of multiple involute-foil segments held between concentric circular ribs, have relatively robust geometries. The oscillating-flow-rig tests of the segmentedinvolute-foil regenerator have demonstrated a shift in regenerator performance strongly in the direction of the theoretical performance of ideal parallel-plate regenerators.

This summary report is largely an integration of text and figures taken from the large project annual reports (refs. 6 and 7), and other project reports. The first author is the NASA technical monitor of the NRA contract. The other authors were all participants in the contract through Phase II, and most are still involved in Phase III; they developed the segmented-involute-foil concept and did the analysis, development and testing summarized here. 


\section{Reasons for, Objectives and Approach of the Regenerator Microfabrication Effort}

Stirling regenerators are usually made of woven screens or random fibers. Woven-screen regenerators have relatively high flow friction. They also require long assembly times which tend to increase their cost. Random-fiber regenerators also have high flow friction but are easy to fabricate and therefore are inexpensive. Figure 1 shows a typical random-fiber regenerator and micrograph close ups of the fibers.

Due to the method of fabrication, the fibers are random primarily in a plane perpendicular to the main flow path. Thus both woven screens and random fibers experience flow primarily across the wires (cylinders in cross flow). Cylinders in cross flow produce flow separation, wakes, eddies, and stagnation zones resulting in high flow friction and thermal dispersion, a loss mechanism that increases apparent axial conduction. Random-fiber regenerators perform substantially worse than ideal parallel-plate regenerators in terms of a regenerator figure of merit. Based on this figure of merit (roughly the ratio of fluid-solid heat transfer to pressure drop, with an adjustment for thermal dispersion - to be discussed later), random-fiber regenerators are worse by a factor of $\sim 4$ compared to ideal parallel-plate regenerators in the Reynolds-number range of interest ( $\sim 50$ to 100). See figure 2 (from refs. 7 and 8$)$ for comparisons of the figures of merit for theoretical parallel-plates and random fibers, plus those of two other concepts to be discussed. The random contact surfaces and porosity variations of random fibers, plus the compressing of fibers used to achieve the desired average porosity, provide concerns about fiber breakage and flow uniformity (reliability and performance concerns, respectively).

So there are incentives to finding a regenerator geometry that more closely approaches that of ideal parallel-plate regenerators. Wrapped-foil approximations of parallel-plates have seemed an attractive concept, but in engine practice they have not proved successful. This seems to be due to the difficulty of wrapping the foils with adequate gap uniformity and maintaining the uniformity when the foils are subjected to the stress of startup, shutdown and normal-operating temperature gradients.
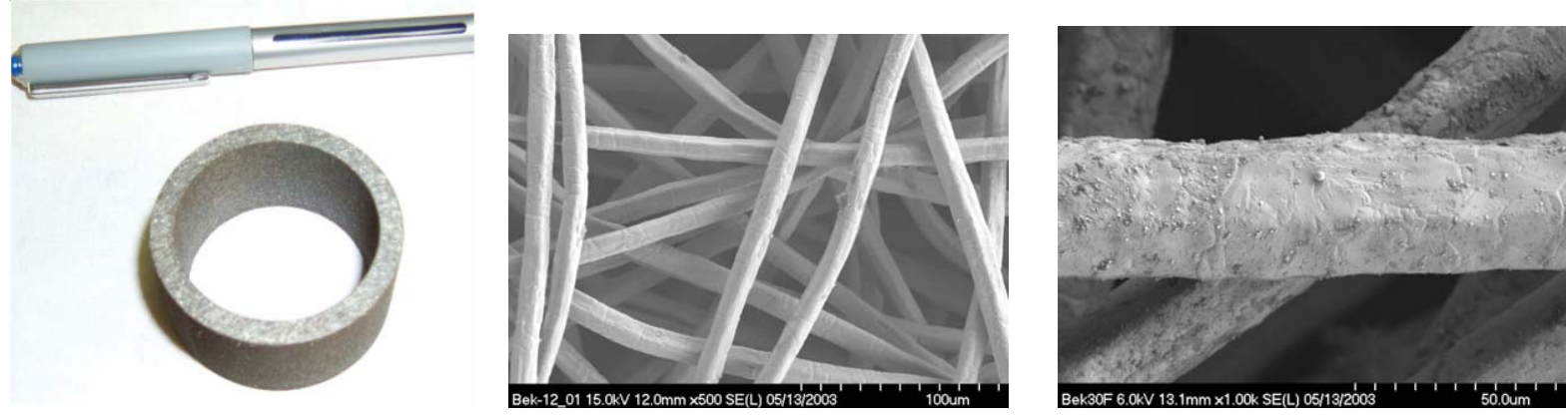

Figure 1.-Random-fiber regenerator and fiber micrographs.

Figures of merit --- various matrices

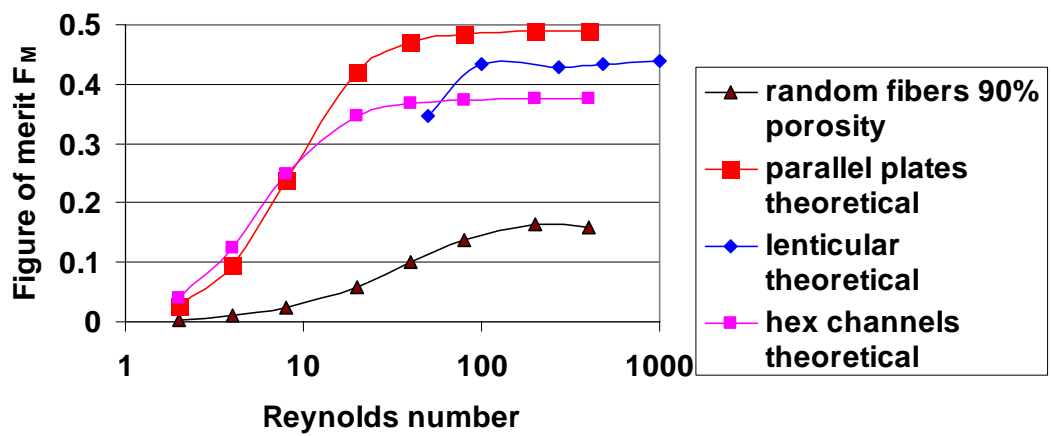

Figure 2.-Figures of merit for various geometries constructed of stainless steel. 
The primary goals of this effort were to (1) identify a more robust geometry having advantages similar to those of parallel-plates, (2) identify a practical microfabrication process (low enough cost, for example), and an organization that could do the fabrication; then make this organization a part of the contractual effort, (3) fabricate and test a prototype regenerator in the oscillating-flow rig, and (4) then fabricate and test a prototype regenerator in a suitable Stirling engine. Originally both oscillating-flow rig and engine testing were to be done in Phase III (3rd year), and the design of an integrated heater/cooler/regenerator was also to be completed based upon the chosen microfabrication process.

Difficulties that led to a change in plans were: (1) NASA funding difficulties made it appear that there would be no Phase III effort; (2) after Mezzo was chosen to use LiGA and EDM to manufacture segmented-involute-foils, it was discovered that EDM could not be used to fabricate the planned stainless-steel prototypes within the allotted time and funding, and (3) it was also realized that the chosen microfabrication process did not lend itself to fabrication of an integrated heater/cooler/regenerator. At the transition from Phase I to Phase II, replanning of Phase II led to (1) plans to fabricate a nickel segmented-involute-foil regenerator via LiGA only and test it in the oscillating-flow rig during Phase II, and (2) dropping the plan to design an integrated heater/regenerator/cooler. Phase II fabrication and testing of the nickel segmented-involute-foil regenerator was completed with excellent results, as will be shown. Then, toward the end of Phase II, funding became available to start a scaled-down Phase III effort to fabricate and test a nickel regenerator in a Sunpower FTB engine. This Phase III effort began in October 2006 and is scheduled to be complete by December 2007.

\section{Concepts Considered During Phase I}

A number of concepts were considered during the Phase I vendor and process survey (refs. 6 and 8 ).

\section{A. Lenticular Arrays}

The initial concept considered was a "lenticular" structure which is shown in a 2-D CFD result schematic in figure 3; the name comes from the lentil- or lens-shaped elements around which the fluid is shown flowing. Previously published computational analyses (ref. 9) showed that the 2-D lenticular structure produced a very good figure of merit; comparisons of a lenticular figure of merit with those of the theoretical parallel-plate, random fiber, and a hexagonal array (to be discussed), are also shown in figure 2 .
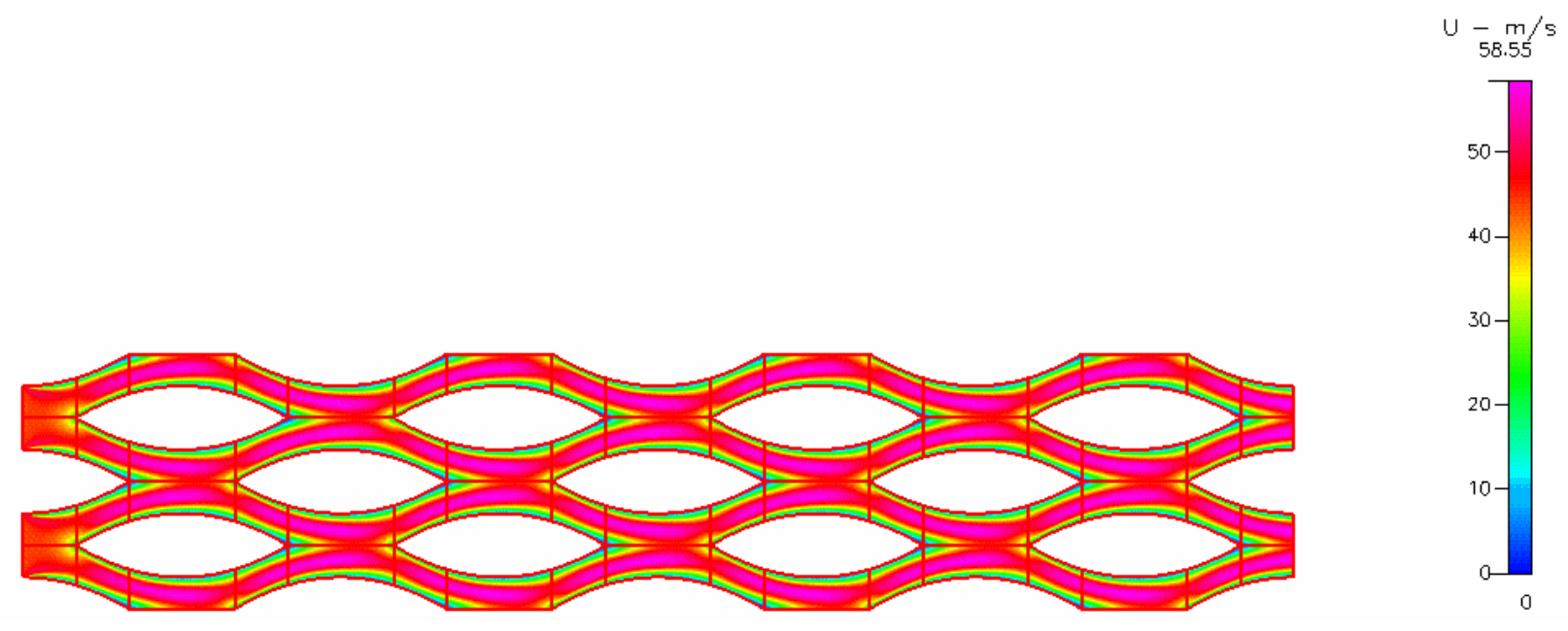

Figure 3.-Lenticular concept. A 2-D representation with CFD calculated velocity contours, shown as simulated by Cleveland State University. The constant-velocity input is at the left. 

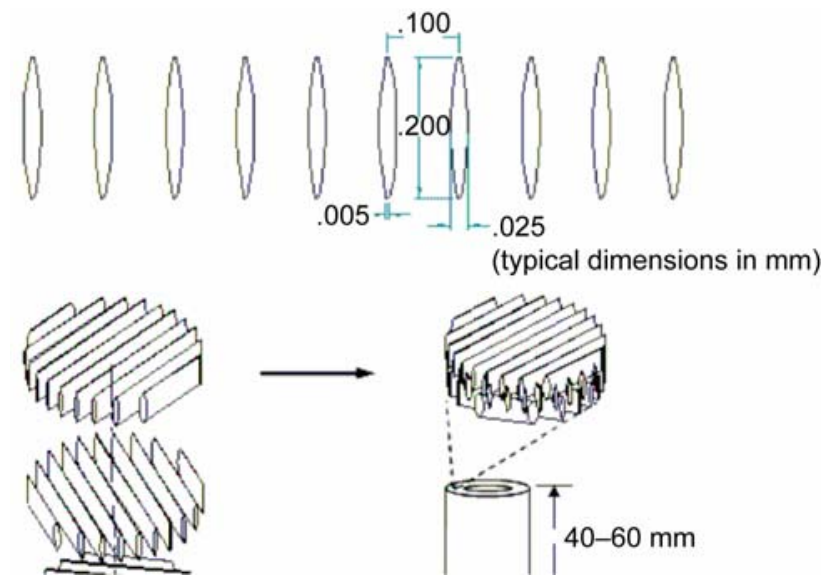

Figure 4.-An attempt at a more practical (fabricable) lenticular array (with adjacent disks rotated $60^{\circ}$ relative to each other).
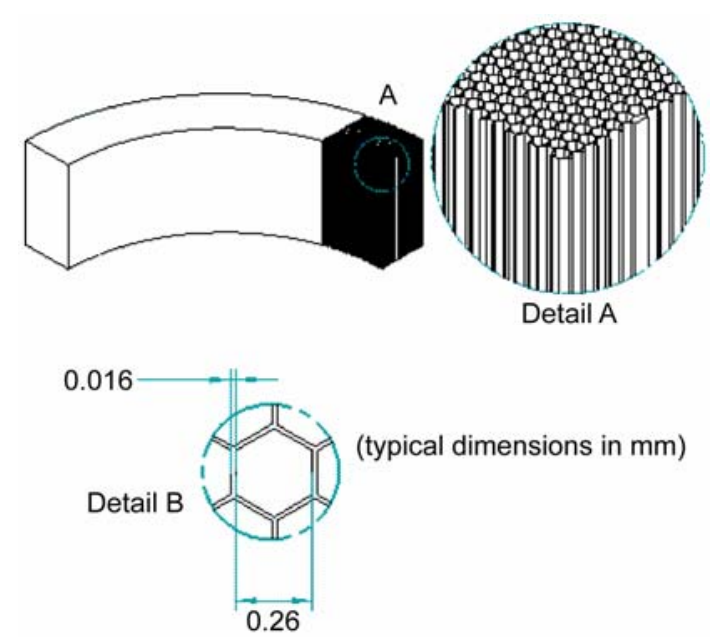

Figure 5.-Honycomb-array geometric concept.

An attempt at a more-practical lenticular concept was to nest together layers of lenticular arrays as shown in figure 4. (Lenticular arrays were considered for annular-type regenerators, also.) Every layer is composed of several parallel lenticular rows. Each layer is rotated relative to the adjacent layers (by $60^{\circ}$ ) and each layer penetrates halfway into the next. In addition to being structurally strong, this array minimizes flow separation and the almost-uniform cross section minimizes flow acceleration and deceleration. It also allows radial flow redistribution among channels, thus accommodating redistribution of any non-uniform entry flow. Unfortunately, after consultation with possible manufacturers, it was found that this lenticular geometry could not be made at reasonable cost by then-current technology, and the NRA team moved on to other concepts.

\section{B. Honeycomb Arrays}

Another concept considered was a honeycomb structure which consists of a network of hexagonal channels as shown in figure 5. The illustrated wall thickness of the honeycomb matrix is $16 \mu \mathrm{m}$ and the space between two parallel walls is $260 \mu \mathrm{m}$. A complete regenerator could consist of a single sheet of hexagonal channels (perhaps $\sim 60 \mathrm{~mm}$ long) or a stack of honeycomb slices. Stacking with offset would allow flow redistribution among channels.

At the time of the Phase I investigation, typical honeycomb structures were manufactured by extrusion processes whereby the overall diameter of a large honeycomb structure is reduced over a number of stages. This process tends to compromise passage uniformity that may have been initially present. It was later learned that thin disks of honeycomb channels had been made by LiGA-EDM, and they had been fabricated in that manner for Stirling cooler application by Mezzo; these are of relatively low-porosity compared to Stirling-engine regenerators. Figure 2 shows the theoretical performance of honeycomb arrays compared to parallel plate and other geometries.

\section{Parallel-Plate-Type Concepts}

Achieving a parallel-plate-type structure that performs close to a theoretical parallel plate has been a goal of regenerator research for a number of years. Many researchers have tried to produce such structures by winding thin metal foils around cylindrical forms, with various spacing elements between layers (wrapped foils). Such regenerators have never performed up to expectations, presumably because of poor uniformity of layer spacing. The required gap between layers is on the order of $100 \mu \mathrm{m}$, which is 
very difficult to maintain within the required 10 percent tolerance (ref. 8) (also see Gedeon's memorandum in App. B of ref. 7) - both during initial assembly and after the effects of thermal distortions. For this NRA microfabricated regenerator, the wrapped-foil was rejected because of its historical record. Also rejected was a variation of the foil-type regenerator consisting of stacked flat-foil elements ${ }^{*}$. Flat elements have the structural problem that if you constrain their length while subjecting them to thermal expansion, they buckle. That is they deflect one way or the other at random with the ratio of lateral deflection to length-wise shortening approaching infinity. Any buckling of a regenerator foil element is undesirable because it affects the spacing between layers. Flat elements also have the problem that they cannot be arranged in an axisymmetric way, leading to potential problems with flow uniformity.

This NRA team felt that a parallel-plate regenerator could likely succeed only with curved elements. The great advantage of curved elements is structural. If a curved element has constrained endpoints while subjected to thermal expansion its curvature changes slightly in a regular way to accommodate the new arc length. It does not buckle. Therefore the spacing between layers is not affected much and any effect on spacing is predictable. At this point, the type of curved parallel-plate structure selected for further study consisted of precisely aligned, thin, curved plates as shown in figure 6 . The illustrated wall thickness is $15 \mu \mathrm{m}$ and the space between two parallel walls is $125 \mu \mathrm{m}$. Similar to the honeycomb regenerator, a complete regenerator could consist of a single sheet parallel-plate structure ( $\sim 60 \mathrm{~mm}$ long) or a stack of parallel-plate slices. Again, stacking could be with offset to allow flow redistribution among channels. The foil elements follow involute curves (ref. 7). An involute of a circle is what you get when you unwind a string from a circular cylinder. It is the curve traced out if you keep the string tight and attach a pencil to the end of the string. A family of such curves spaced by constant rotational angle increments (shortening the string by increments) has the property that the normal distance between curves (the gap) is constant along the curve. So involute curves are a way to pack foil with the desirable property of uniform gap.

The main problem with the involute-foil regenerator concept illustrated in figure 6 was that a manufacturer that could make it could not be found.
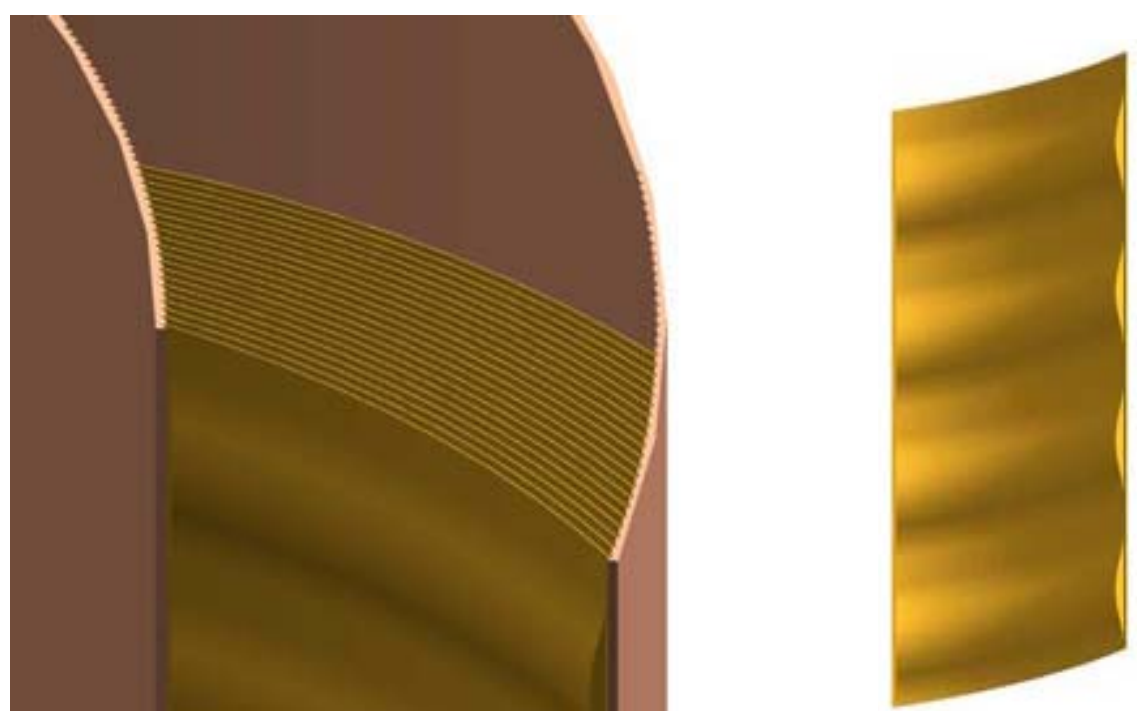

Figure 6.-Original involute-foil geometry (could not find a manufacturer for this geometry).

*The following discussion of the relative merits of flat and curved foils is taken from a discussion of David Gedeon's in reference 6. 


\section{Selected Segmented-Involute-Foil Concept}

To increase structural integrity it was decided to design the curved foil elements to be relatively short (i.e., segmented foils) and to package them within concentric rings. The ratio of foil element length to spacing gap is an important design criterion. A ratio on the order of 10 is a rule-of-thumb criterion for a good approximation to parallel-plate flow. The concentric-ring approach adapts well to the thin-annular regenerator canisters used for small space-power-type Stirling convertors. In that case there might be only a few concentric rings of elements between the inner and outer walls. For testing purposes the geometry could be extended to almost completely fill a cylindrical canister, as appropriate for oscillating-flow rig testing. The initially chosen segmented-involute-foil structure is illustrated in figure 7.

Adjacent disks were to be arranged as shown in figure 8. All disk were too be identically manufactured, but adjacent disks would be "flipped" so that the involute-foil segments of adjacent disks would cross at angles approximating $90^{\circ}$. This crossing of involute segments would help avoid channeling of flow. However, the rings in adjacent disks would still line up, meaning that flows in different concentric rings might not be uniform.
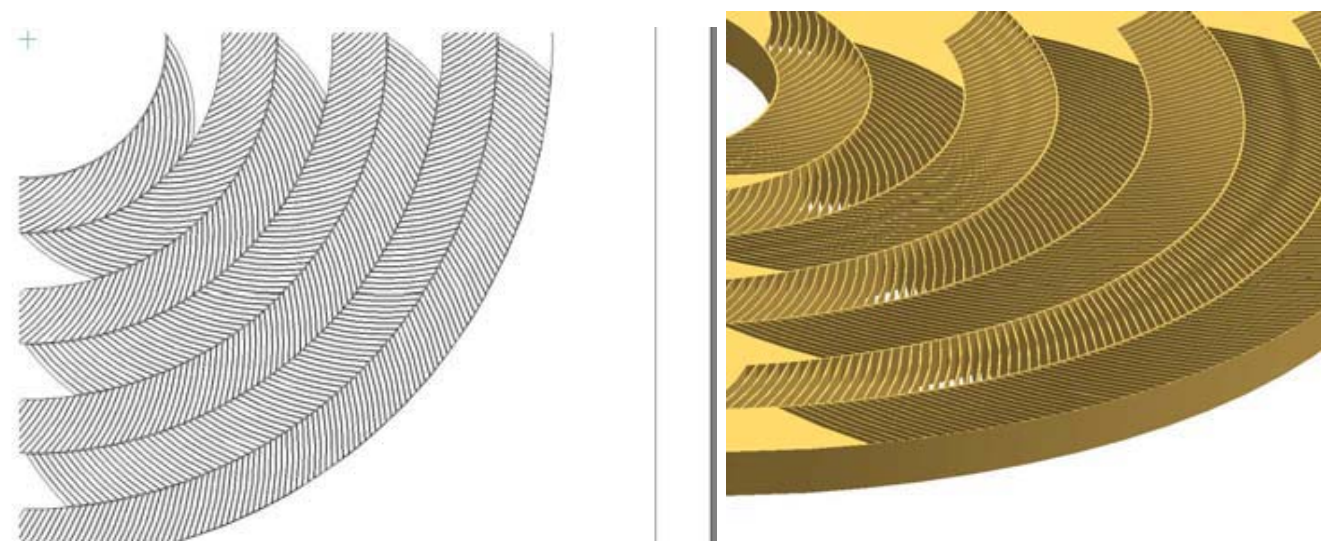

Figure 7.-Original segmented involute-foil concept, with axial view on left and solid model of annulus on right.

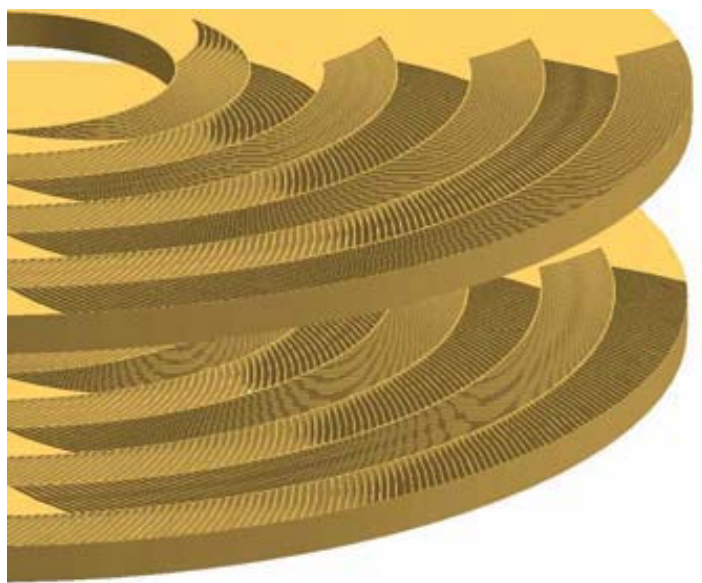

Figure 8.- Stacking of disk annuli in original segmented-involute-foil concept. Here, all disk annuli are identically manufactured, but adjacent annuli are "flipped." 
The concern of having non-uniform flows in different concentric rings led to a further evolution of the segmented involute-foil concept, as illustrated in figure 9. Figure 9 shows sectors of two types of disk annuli. (These are actually schematics of two of the 30 times actual size involute-foil sectors tested in the Large Scale Mockup at the University of Minnesota.) In each of these sectors of figure 9, the involute-foil segments are all now angled in the same general direction from inner to outer rings. But the sector on the left is a 6-rib (or ring) sector and the sector on the right is a 7-rib sector. So, now when adjacent disks (or sectors of disks in the LSMU) are stacked, the rings do not line up and the axial flow can redistribute from ring-to-ring. A frontal view of two layers of the two types of annuli is shown in figure 10 .

In figure 9, the average angle-of-tilt of the involute-foil segments relative to the horizontal increases from inner to outer rings. Thus the channel length to gap ratio varies somewhat from inner to outer rings. Also, for the 7-rib foil of figure 9, the foil segments for the inner and outer half-rings would be approximately half the length of those in the inner and outer rings of the 6-rib foil. These variations in involute-foil angle and length also hold for the actual-size involute foils. Details of the involute mathematics are derived by David Gedeon in Appendix E of reference 7.
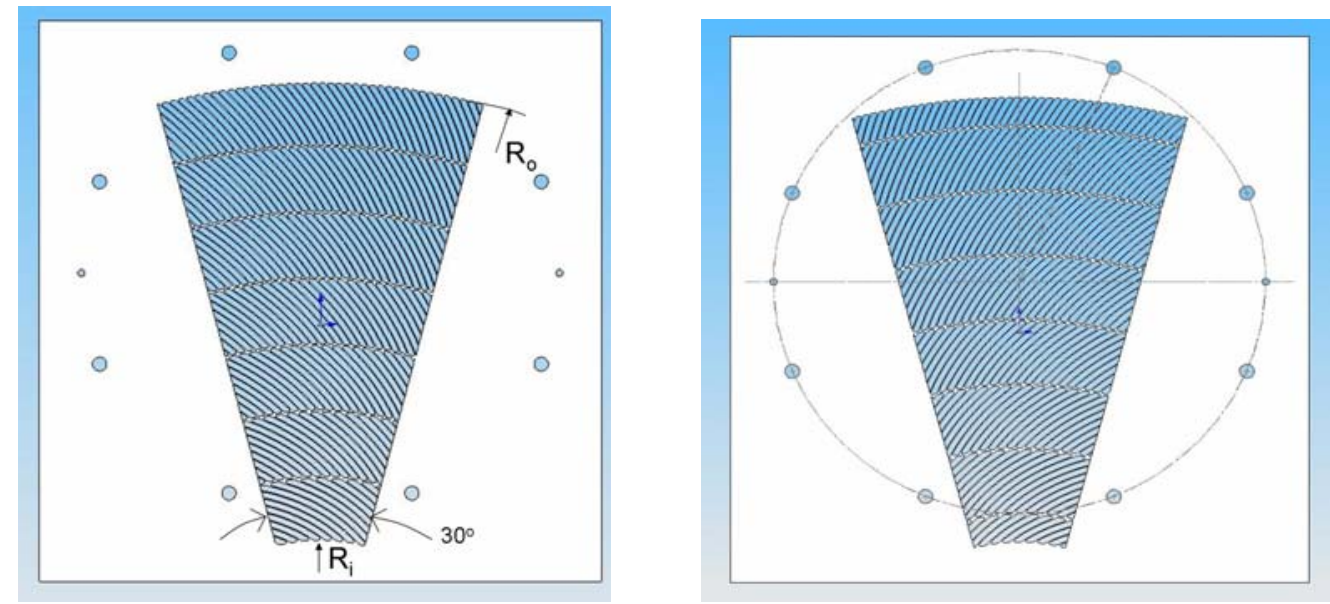

Figure 9.-The two types of LSMU involute-foil patterns. Six rib (or ring) pattern on the left. Seven rib pattern on the right. These involute-foil patterns are the same as used in the actual-size involute-foils (which consist of full disk annuli, rather than the LSMU sectors-ofannuli shown here).

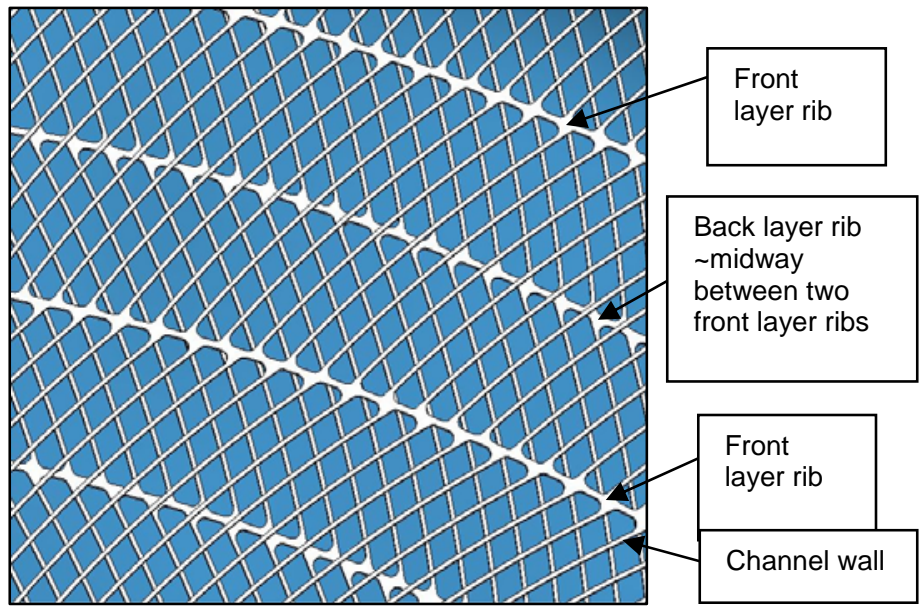

Figure 10.-Frontal view of two layers of microfabricatedsegmented-involute foil. The other layers are repeats of these two types of layers. 


\section{Prototype Regenerator Fabrication (International Mezzo Technologies)}

\section{A. Microfabrication Process Background}

The combination of LiGA and EDM theoretically provides a means to fabricate high-aspect-ratio microfeatures normally associated with the LiGA process, out of any conducting material. The initial research plan involved using the LiGA process to fabricate well-defined, high-aspect-ratio EDM tools. These LiGA-fabricated EDM tools would then be used to make the micro-machined regenerator parts from materials with the desired high-temperature properties and low thermal conductivity (stainless steel, Inconel, etc.). EDM tools were fabricated via LiGA and efforts to EDM parts from stainless steel showed initial promise in terms of being able to produce the correct geometry, at least at shallow depths. But the process was very slow, tool wear rate was high, and it became apparent that the probability of fabricating the desired stainless-steel regenerator using LiGA-EDM with the available funding was low.

To fabricate the regenerator on schedule the standard LiGA process was used to directly produce individual nickel regenerator components which were then assembled, and subsequently tested in the oscillating-flow rig. This also supported the desire to move the oscillating-flow rig testing from Phase III (year 3) to Phase II (year 2) - since available Phase III funding for this and other NRA contracts was in jeopardy. This section provides a summary of the successful effort that resulted in manufacture via the LiGA process of the electroplated-nickel regenerator that was tested in the oscillating-flow rig. More information about the EDM trials and material removal rates is given in reference 7.

\section{B. The LiGA Manufacturing Process}

Two closely related LiGA processes are described below. One is referred to as the "optimal" process that was originally envisioned, the other describes the process that was actually followed. The difference between the two processes is associated with unanticipated problems in the development component of the lithographic patterning of the polymethyl methacrylate (PMMA, or Plexiglass type plastic) templates.

In an optimum LiGA exposure-development sequence, the sidewalls of the lithographically-patterned PMMA template are straight. In this project, unexpected difficulties developing the PMMA resulted in excess material removal, or "undercutting," at the PMMA-substrate interface. This undercutting led to a more complicated two-step electroplating process and an extra step involving wire EDM. Because of "undercutting" during the development process, the following process was used to fabricate the regenerator components (schematics illustrating the process are given in reference 7):

1. An X-ray mask was fabricated. The mask consisted of a tightly packed array of nineteen regenerator disk patterns.

2. A $250 \mu \mathrm{m}$-thick sheet of PMMA was bonded to a 400-series (magnetic) stainless steel substrate.

3. An x-ray lithography-electroplating process sequence was used to produce the nickel regenerator disk parts. It was found that development of the exposed PMMA caused some unexpected, undesired "undercutting" at the PMMA-substrate interface. Undercutting is associated with excess PMMA being dissolved during the development process. This fact motivated a two-part electroforming process. A copper electrodeposition step was used to fill the bottom of the features with copper to a depth equal to the height of the undercutting region. Beyond this point, nickel was deposited. To ensure that all these voids were completely filled with metal, the electroplating process was continued after all the features were filled, resulting in an overplated deposit. (Undercutting occurred on one side of the disk and overplating on the other.)

4. Initially, polishing was tried to remove the overplated layer. The polishing was found to destroy parts, so an alternative process was used and found to be successful. This successful process involved attaching the conductive substrate to a magnetic chuck, and orienting the substrate in the vertical plane. Then a wire EDM was used to take a "skim pass" just above the non-conductive PMMA layer. This step removed the overplated nickel. The substrate was then released from the chuck. 
5. At this point, the nickel and copper electrodeposited features and the remaining PMMA was debonded from the substrate and the unexposed PMMA was dissolved in acetone. The remaining nickel-copper features were again attached to the magnetic chuck with the nickel features in contact with the chuck. A second EDM process was used to remove the copper and nickel in the "undercut" region. It should be noted that if the copper had completely filled the "undercut" region, the copper could have been removed with an etch, leaving only nickel parts with the desired geometry. However, it was found that insufficient copper was deposited to fill the "undercut" region. As a result, some nickel was also deposited into the "undercut" region, making it necessary to use a second EDM "skim cut" to remove both the nickel and copper within the "undercut" region. Following the second EDM "skim cut" the parts were released from the chuck and inspected.

\section{The Fabricated Oscillating-Flow-Test-Rig Regenerator}

The previously described process was used to fabricate the regenerator tested in this project. Micrographs of typical parts are shown in figure 11(a) to (d). The nickel webs are approximately $15 \mu \mathrm{m}$ in width, and arranged in an involute pattern (fig. 11(a) and (b)). The thickness of each disk is approximately $250 \mu \mathrm{m}$. Figure 11(c) shows a single involute-foil slipped onto the stacking fixture. Figure 11(d) shows a single disk leaning against the outer housing of the regenerator. Figure 12 shows the final regenerator that was tested in the oscillating-flow test rig.

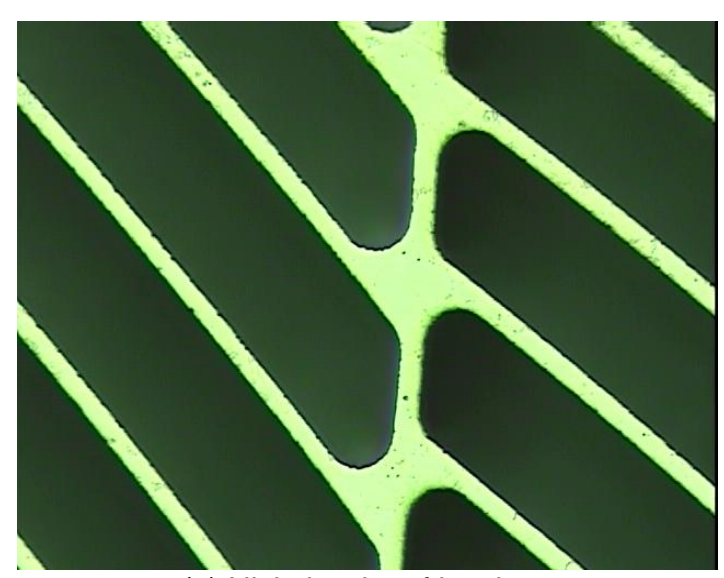

(a) Nickel webs of involute.

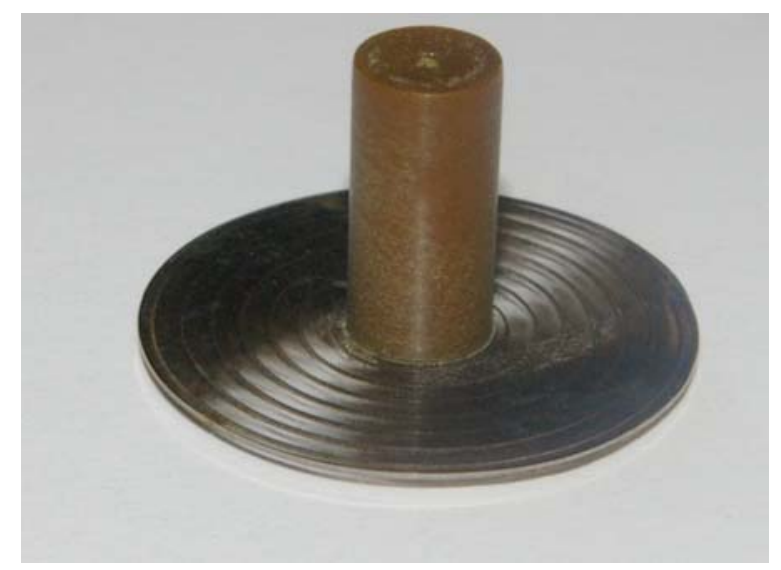

(c) Disk stacked onto fixture.

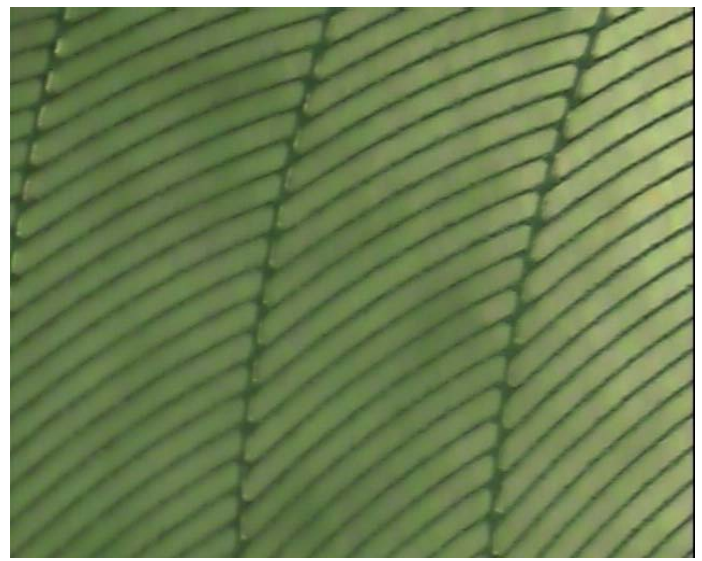

(b) Lower magnified view of involute pattern.

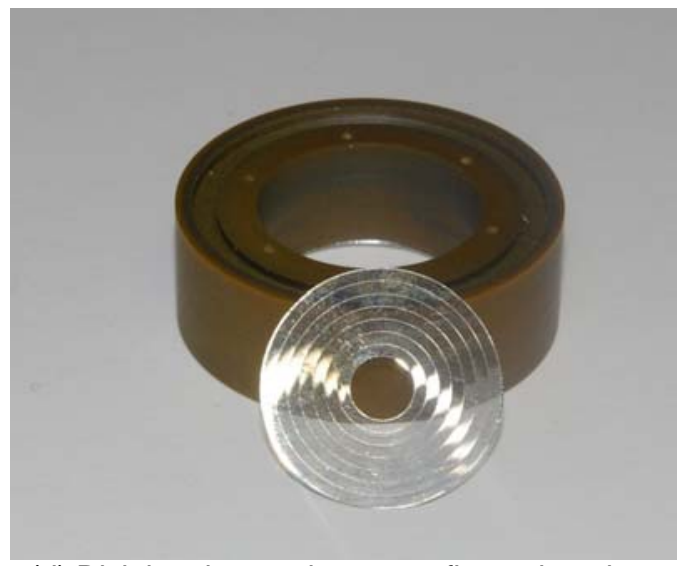

(d) Disk leaning against outer fixture housing.

Figure 11.—Different magnified views of regenerator disks. 


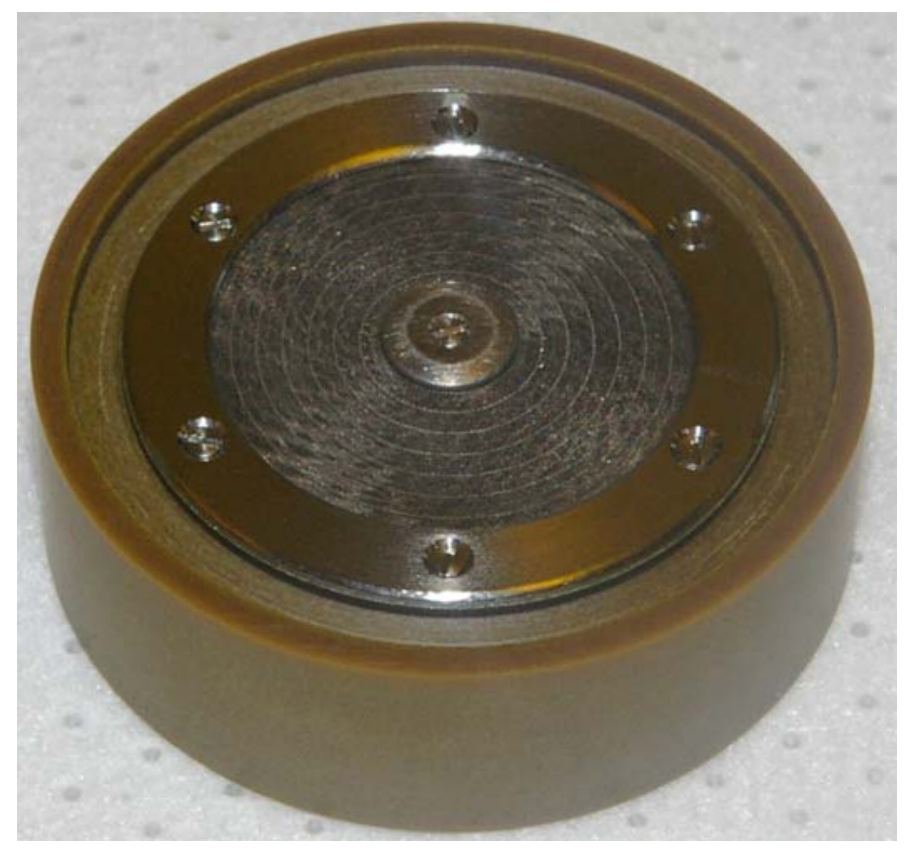

Figure 12.-Assembled oscillating-flow rig regenerator (stack of 42 disks).

\section{Prototype Regenerator Testing and Data Analysis (Sunpower Incorporated and Gedeon Associates)}

The oscillating-flow rig is located at Sunpower in Athens, Ohio, via a loan agreement with NASA Glenn Research Center. Sunpower did the testing and Gedeon Associates did the data analysis.

The CAD rendering of figure 13 shows a typical single flow channel of the regenerator tested in the oscillating-flow rig. It is from an early solid model and does not correspond exactly to the final matrix geometry. Table I gives dimensions corresponding to the final matrix (with the channel width being a typical width, since width varies somewhat from ring to ring).

The results of testing in the oscillating-flow rig were very promising and are compared with theoretical parallel-plate results in figure 14 (from ref. 7), along with the test results of several other regenerator types. The Mezzo-fabricated segmented-involute-foil regenerator has a figure-of-merit substantially higher than the other tested regenerator types - including the 90 percent random-fiber regenerator which is roughly what is being used in the current generation of small space-power Stirling engines (in the 50 to 100 Reynolds number range). The 96 percent porosity random-fiber data is also the result of recent testing in the oscillating-flow rig.

The figure-of-merit definition is given in figure $15^{*}$. This definition is a revision of earlier figures of merit to include the effects of thermal dispersion conduction enhancement, $N_{k}$. The figure of merit is a first-cut measure of overall regenerator performance. Plots of the friction-factor, Nusselt number and thermal dispersion conduction enhancement correlations as functions of Reynolds number that were used to plot the involute-foil figure of merit are given in reference 7. Also, implications of this figure of merit for actual Stirling engines are discussed by Gedeon in Appendix F of reference 7.

\footnotetext{
*From "Regenerator figure of merit," a memorandum to the NRA team from David Gedeon, August 16, 2003.
} 


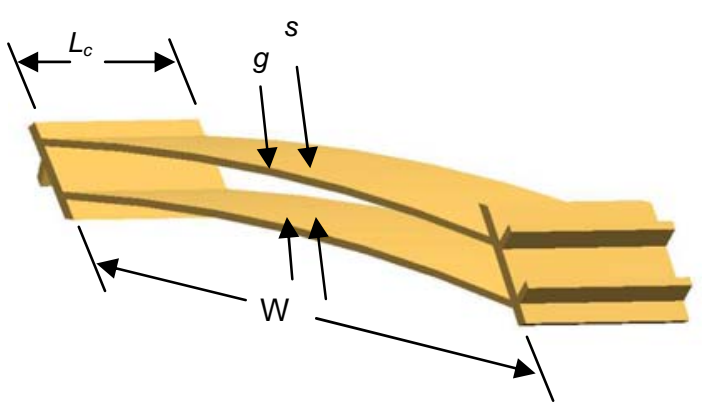

Figure 13.-Typical segmented-involute-foil channel, of one layer. Dimensions corresponding to labels are given in table I.

TABLE I.-INVOLUTE-FOIL-CHANNEL DIMENSIONS (SEE FIG. 1)

\begin{tabular}{|l|l|l|}
\hline Dimension & Unit & Value \\
\hline gap, g & micron, $10^{-6} \mathrm{~m}$ & 86 \\
\hline gap+wall, s & micron & 100 \\
\hline Wall thickness, s-g & micron & 14 \\
\hline Channel width, $\mathrm{W}$ & micron & 1000 \\
\hline disk (layer) thickness, Lc & micron & 265 \\
\hline porosity & & 0.838 \\
\hline Hydraulic diameter, Dh, 4A/P & micron & 162 \\
\hline
\end{tabular}

Figures of merit --- various matrices

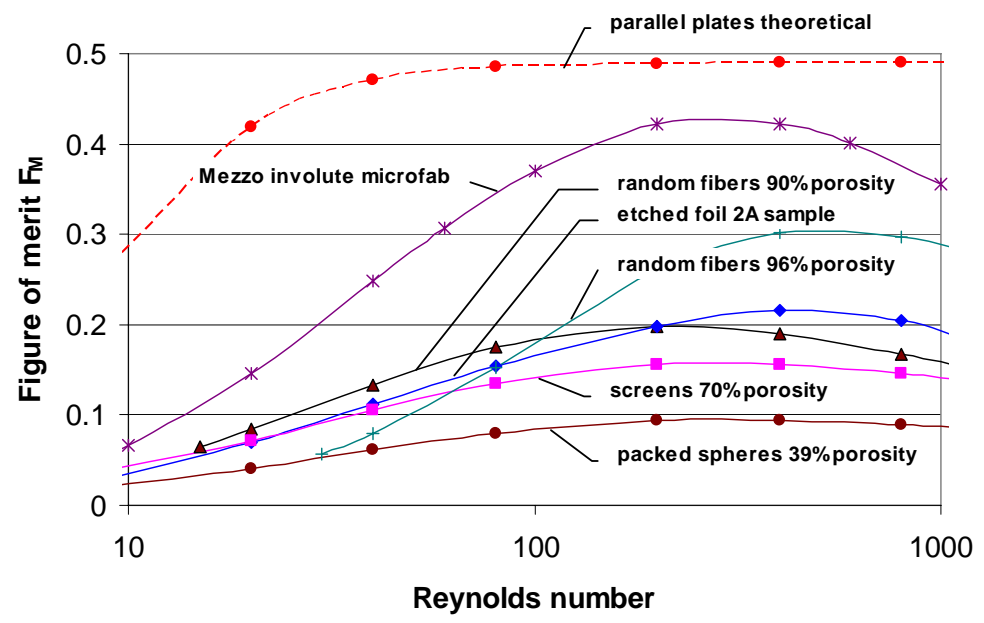

$$
\begin{aligned}
F_{M}= & \frac{1}{f\left(\frac{R_{e} P_{r}}{4 N_{u}}+\frac{N_{k}}{R_{e} P_{r}}\right)} \\
R_{e} & \text { Reynolds number } \\
P_{r} & \text { Prandtl number } \\
f & \text { Friction factor } \\
N_{u} & \text { Nusselt number } \\
N_{k} & \text { Thermal dispersion conduction }
\end{aligned}
$$

Figure 15.--Regenerator figureof-merit definition.

Figure 14.-Figure-of-merit test results as functions of Reynolds number for various matrices, compared with that for theoretical parallel plates (prepared by Gedeon, taken from ref. 7). 


\section{Other Important Analytic Results (Gedeon Associates)}

Several important analytical results will be briefly discussed here, with references to further details.

\section{A. Performance Estimates for a Stirling Engine with an Involute-Foil Regenerator}

The 1-D Sage Stirling performance and design code (ref. 5) was used to estimate the impact on performance of optimizing a Sunpower FTB engine for use of an involute-foil regenerator. These estimates suggest that, relative to the original random-fiber-regenerator FTB design, use of an involutefoil regenerator might result in an enhancement of performance (power and efficiency) by 6 to 9 percent (see Appendix C in ref. 7).

Sage was also used to look at the impact of using an involute-foil in an FTB with several progressive changes to the engine - since limited funding will not allow complete FTB engine optimization for the Phase III involute-foil testing (see section 3.6.5.1 in ref. 7). This helped define needed FTB hardware modifications for Sunpower, and the needed involute-foil envelope dimensions for Mezzo. For example, since the involute-foil has substantially lower pressure drop than random fiber - to avoid redesigning the FTB displacer rod (and dynamics), it is necessary to add pressure drop back into the FTB-with-involutefoil-regenerator (probably via changes to the acceptor-heat-exchanger design).

\section{B. Radiation-Loss Theoretical Analysis}

As an action item from the Phase I review, the team was asked to look at the potential radiation loss directly through the involute-foil regenerator. The concern was that with a defined, non-random, geometry there might be a significant direct-view path through the involute-foil regenerator.

The radiation loss through a long, thin tube was analyzed and, by analogy, conclusions were drawn for the involute-foil regenerator. The details of this analysis are given in section 3.6.5.2 and Appendix A of reference 7 . The conclusions of the study were that for a worst-case radiation flow of $18 \mathrm{~W}$ at the hot end, the radiation flow near the hot end would drop to only $\sim 200 \mathrm{~mW}$ and near the cold end would drop to about $10 \mathrm{~mW}$. Thus the direct radiation loss through the involute foil would be smaller by two orders of magnitude than an estimated $\sim 13 \mathrm{~W}$ enthalpy-flux loss and an $\sim 7 \mathrm{~W}$ solid-axial-conduction loss.

Cleveland State University also made CFD calculations to check these results and also concluded that the direct radiation loss would be negligible.

\section{Impact of Solid Conduction in Segmented-Foil Regenerators}

One of the benefits of the segmented-involute-foil design was thought to be that it interrupts the solid thermal conduction path. Analysis showed that the truth is more complicated and depends on the disk thickness, the solid thermal conductivity and also the properties and Reynolds number of the gas flowing through it (see section 3.6.5.3 in ref. 7, for a more complete discussion of this subject).

In one extreme, coupling between the regenerator gas and solid bridges the contact resistance between segments. This produces solid conduction in individual segments approaching that of a continuous foil. For example, as the lengths of the segments increases, this tends to occur. (In the limit of one long segment, it becomes a continuous foil.) In the other extreme, high thermal conduction within each segment produces a stair-step solid temperature distribution with distinct temperature gaps between segments, increasing the net enthalpy flow down the regenerator.

For the Mezzo segmented-involute-foil regenerator, with the relatively high nickel conductivity, the segments are sufficiently short that the solid conduction is never more than about 8 percent of continuousfoil conduction. Thus the high contact resistance produced by the chosen patterns and stacking method, does block most of the solid conduction. 
Cleveland State University also did CFD analysis of flow through layers of segmented parallel plates, and showed that this will produce a close approximation of flow through segmented-involute foils. The CFD results support the conclusions of Gedeon (see section 6.1 in ref. 7).

Overall it was determined that use of the higher conductivity nickel, instead of stainless steel, does increase axial thermal losses through the regenerator, but only by $\sim 4$ percent according to CFD analysis. Also, it would not be desirable to double the length of the involute-foil segments (though this is exactly what is being done in Phase III, primarily due to funding limitations; i.e., instead of using $250 \mu \mathrm{m}$ disks, as for the oscillating-flow rig tests, half as many $500 \mu \mathrm{m}$ disks will be used — to get the desired regenerator length for the FTB engine, in order to limit cost).

\section{Survey of Microfabrication Processes and Vendors, and Large-Scale- Mockup Design and Testing (University of Minnesota)}

During the Phase I effort, a survey was made of potential microfabrication processes and vendors for an improved regenerator concept (refs. 6 and 8). Choice of the concept, and the vendor and process, were interactive considerations. For example, it was found that the originally-preferred lenticular concept could not be made by anyone with acceptable cost. Eventually International Mezzo Technologies of Baton Rouge, Louisiana was chosen to microfabricate the segmented-involute-foil concept.

Also, some important space and time resolved details of the flow and heat transfer cannot be measured in an engine regenerator. So, the 2 nd year (Phase II) began with the design of a large-scale (30 times actual size), dynamically-similar mockup of the microfabricated regenerator for testing with higher spatial and temporal resolution than afforded by the actual-size involute foils. The UMN largescale oscillating-flow regenerator facility (the LSMU) was used to measure frictional pressure drop, time and space resolved heat-transfer rates, and the unsteady matrix flow and thermal interactions associated with jets entering the matrix from passages of adjacent heat exchangers. The use of dynamic similitude was verified by agreement of flow and heat transfer measurements from the LSMU with those from the oscillating-flow rig. (Also see reference 10 for a more complete discussion of LSMU dynamic similitude.)

\section{A. UMN Test-Facility Description}

A picture of the UMN Scotch-yoke oscillatory-flow generator (ref. 11) is shown in figure 16. A schematic of the test section containing the involute-foil test plates is shown in figure 17. Note that a

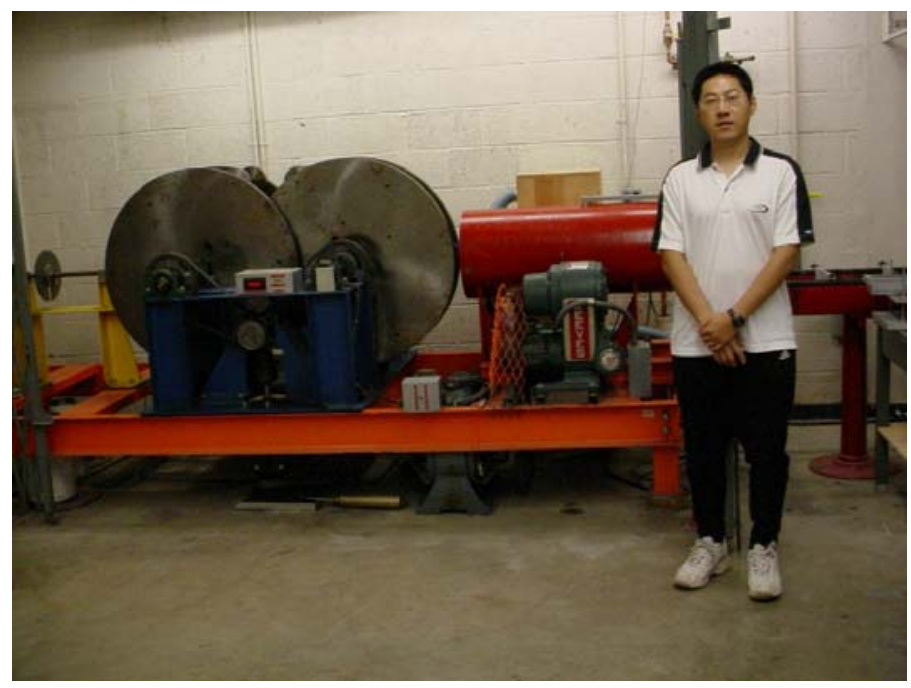

Figure 16.- UMN Scotch-yoke oscillatory-flow generator. Two large flywheels are on the left. The large red cylinder on the right contains the piston. 


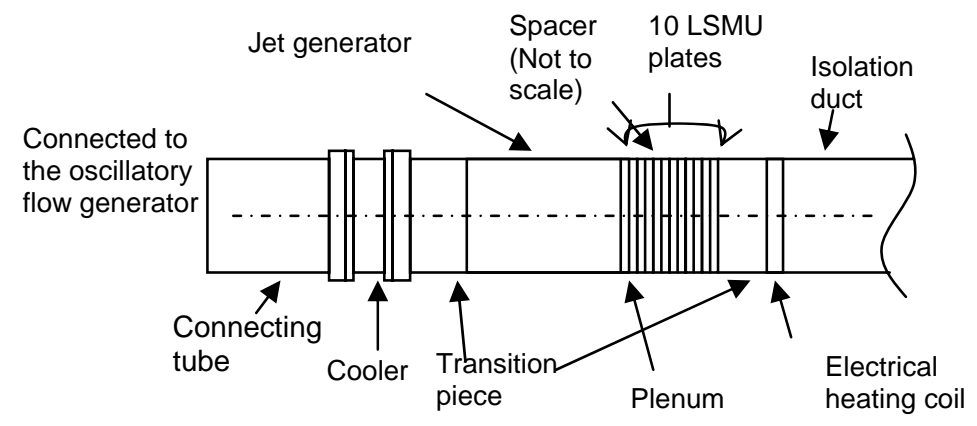

Figure 17.- Schematic of the UMN large-scale (30x) involute-foil test section.

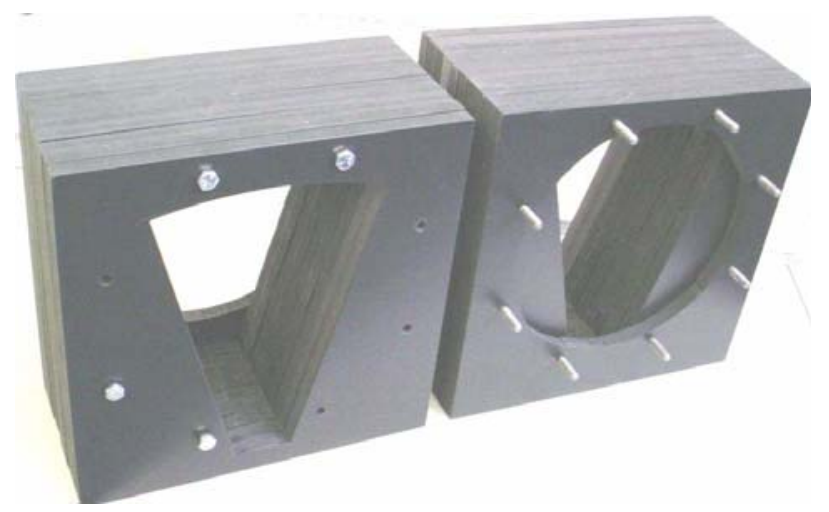

Figure 18.-Two transition sections (without screens).

cooler and an electrical heating coil are used to establish a temperature gradient across the regenerator (LSMU plates) section-from 313 to $303 \mathrm{~K}$, for temperature and heat-transfer measurements. The oscillating air within the test section communicates via the isolation duct with the air in the room. The piston stroke and diameter, and the operating frequency $(0.2 \mathrm{~Hz})$ were chosen to match Valensi and Reynolds numbers of a pattern Stirling engine. More details of the design, operating conditions and results are given in references 7 and 10.

The microfabricated regenerator is of an annular design that cannot be scaled up in its entirety to a factor of 30 and still be operational in the UMN oscillatory test facility. Thus, only 30 degree sectors (shown earlier in figure 9) were used for experimental modeling. Transition sections are required from the circular cooler section to the 30-degree-sector test section and to the circular isolation duct, as indicated in figure 17. Figure 18 shows photographs of the two transition sections, without flow-diffusion screens between the transition segments.

Throughout this effort comparisons among actual-scale oscillating-flow rig results, UMN large-scalemockup test-rig results (oscillating- and steady-flow), 1-D Sage code predictions, and 2-D and 3-D CFD modeling of actual- and large-scale involute-foils have helped understand various test and predicted results and have provided confidence in conclusions from these results. Large-scale timevarying test-rig measurements, such as gas velocities in the regenerator plenums and, gas and solid temperatures within the matrix are not available in the actual-scale test rig. These measurements were used to determine time-varying heat fluxes and Nusselt numbers between fluid and solid within the regenerator matrix, and the time-varying depth of penetration of round and slot jets into the involute-foil matrix. Details of these measurement results can be found in references 7 and 10 .

LSMU unidirectional-flow pressure-drop results were also a valuable source of information for making friction factor comparisons with actual-size involute-foil and other matrix geometry test results, test correlations from the literature for parallel plate configurations, and the effects on pressure drop of double-plate thicknesses, and other numbers of aligned and alternating plates, etc. Figure 19 shows the set 


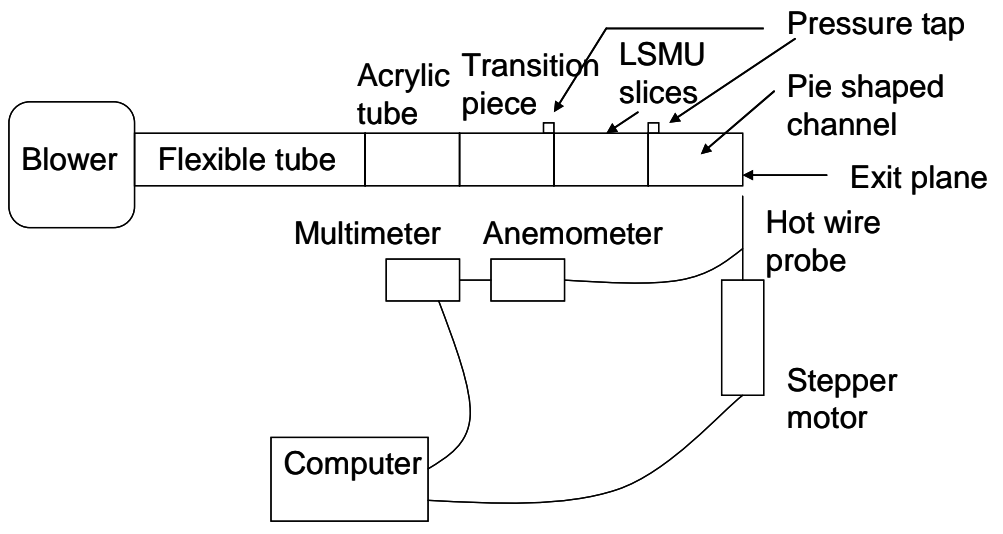

Figure 19.- The schematic of the experimental setup of unidirectional flow test.

up of the experiments under unidirectional flow. At one side of the LSMU slices, the transition piece is

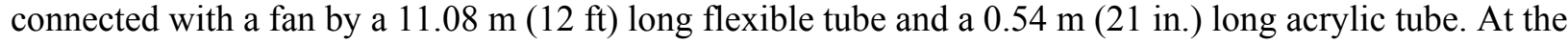
other side, the transition piece connects the LSMU plates with a sector-of-an-annulus shaped opening. The transition piece is for transitioning from a round to a sector-of-annulus cross section. It consists of 9 layers with the sector-of-annulus shaped opening and one layer with the round opening, which are shown in figure 18. The thickness of one layer is $12.7 \mathrm{~mm}(0.5 \mathrm{in}$.). Screen material (not shown in fig. 18) is sandwiched between every two layers to help with the flow diffusion. The pressure drop across the LSMU layers is measured by a micro manometer. The hot-wire anemometer is used to measure the velocity of the outlet flow. The voltage readings of the anemometer are input to the multimeter and then collected by the computer.

\section{B. UMN Large-Scale Unidirectional-Flow Test Rig Results}

Figure 20 shows a comparison of an LSMU Darcy-friction-factor correlation with a correlation from the NASA/Sunpower oscillating-flow rig. The LSMU correlation is $\sim 15$ percent higher at the low end of the Reynolds number range, and about 25 percent lower at the high end (Reynolds number $\sim 1000$ ). The LSMU is higher at the low end of the Reynolds-number range due to the shortness of the LSMU test section (incomplete flow development). The correlation for the actual-size involute-foils may be higher at the high-Reynolds-number end due to some roughness that was observed at certain locations in the actualsize test section, due to debris associated with wire-EDM cutting of overplating at one side of the LiGA formed disks (it is anticipated that such rough regions will be eliminated via improvement in this new process).

The Darcy velocity in the LSMU layers (i.e., the approach velocity to the LSMU) was measured with 8 plates or layers in the LSMU. The local velocity inside the channels is calculated by dividing the Darcy velocity by the porosity. The Reynolds number is based on the local velocity inside the channels and the hydraulic diameter of the channels, which is $4.87 \mathrm{~mm}$. Also the pressure drop across the LSMU test section was measured. The resulting Darcy friction factor as a function of Reynolds number is compared with several other correlations in figure 21; figure 22 shows the same correlations as in figure 21 , but plotted on a log scale. The woven-screen and random-fiber correlations from the Sage code (ref. 5) are based on 90 percent porosity. The staggered-plate correlation (ref. 12) is based on 90 percent porosity, also, while the porosity for the LSMU layers is 86 percent. The continuous-channel correlation is based on laminar flow in a continuous channel with dimensions similar to those of the average LSMU channel. The LSMU segmented involute-foils have substantially lower friction-factors than random fiber and wire screen in the usual Reynolds number range of interest ( $\sim 50$ to 100) for current random-fiber-regenerator engines. 


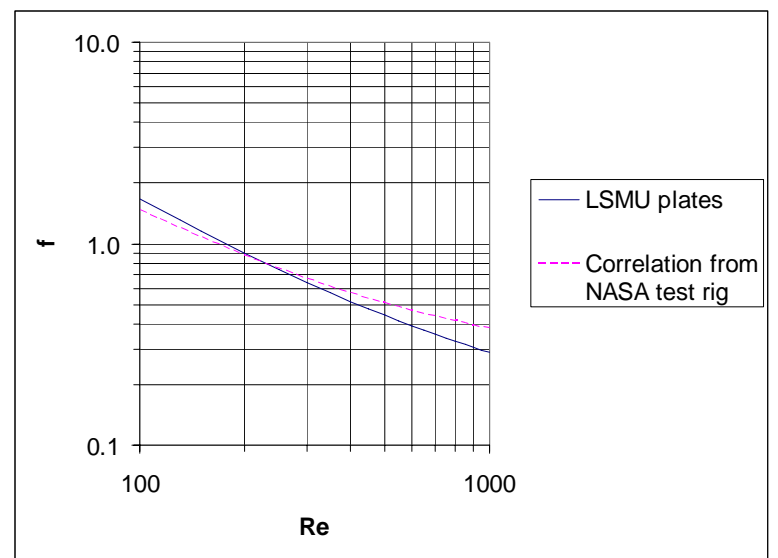

Figure 20.-Comparison of the Darcy-friction-factorsas-functions-of-Reynolds-number correlations for the LSMU and the actual-size involute-foil regenerators.

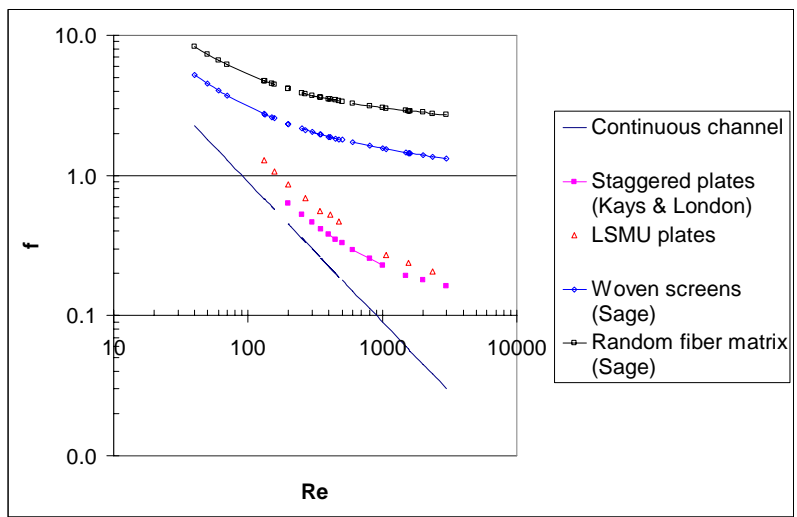

Figure 22.-Darcy friction factors as a functions of Reynolds number for different geometries in log scale. Reynolds number is based on local velocity and hydraulic diameter.

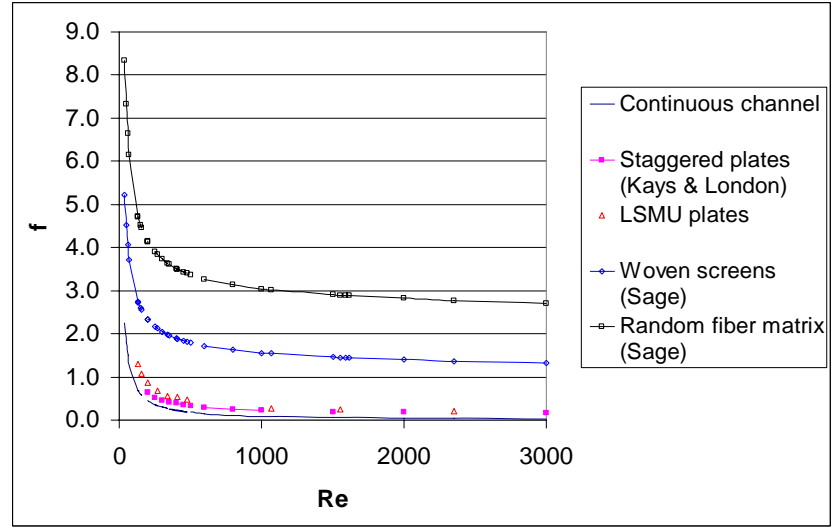

Figure 21.-Darcy friction factors as functions of Reynolds number for different geometries. The Reynolds number is based on the local velocity and hydraulic diameter.

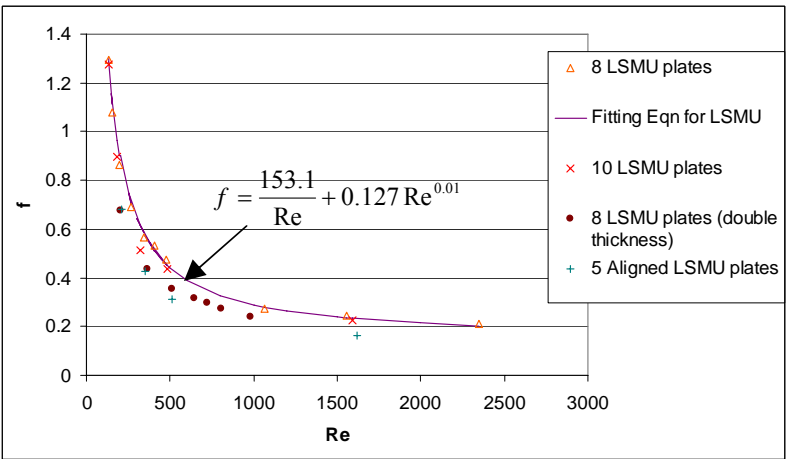

Figure 23.-Comparison of Darcy friction factors as functions of Reynolds number for various LSMU-plate configurations.

Figure 23 shows the comparison of Darcy friction factors of various LSMU plate configurations, including 8 LSMU plates, 10 LSMU plates, 5 aligned LSMU plates, and 8 LSMU plates (double thickness). For the "aligned" test, five 6-rib LSMU plates are stacked together and tested under unidirectional flow. The fins are aligned throughout the entire area. The total thickness of the 5 plates is $39.7 \mathrm{~mm}$. The hydraulic diameter, $d_{h}$, of the flow channel is $4.87 \mathrm{~mm}$. The ratio of the length to the hydraulic diameter is 8.15 . For laminar flow in a continuous channel, the ratio of the entrance length to the hydraulic diameter is $0.06 *$ Re. Under the test conditions, the Reynolds number varied from 207 to 1618. Thus, the entrance length changed from $12.4 d_{h}$ to $97.1 d_{h}$ and the flow of the 5 aligned plates was in the developing regime. Figure 23 shows the aligned plates have lower friction factor values than those for the standard LSMU plate arrangement. This is because the flow through the aligned plates is continuous and has minimal flow separation whereas the LSMU plates under the standard arrangement would have wakes from trailing edges and separation on leading edges.

A comparison can be made between the case where 10 LSMU plates are stacked under the standard configuration and the case where 8 LSMU plates are stacked similarly. The two cases compare very closely. The shorter assembly has only slightly larger friction factor values. This is an indication that the flow develops rapidly within the assembly, perhaps in the first 3 or 4 plates. The fitting equation for friction factor versus Reynolds number for the 8 LSMU plates is shown in figure 23. This equation fits the 10 LSMU plate data also. 
To determine what the friction factor would be with the LSMU geometry but with plates that are twice as thick, we stacked two 6-rib plates together and two 7-rib plates together, and then repeated, giving 4 groups within the eight LSMU plates (or the equivalent of 4 double-thickness plates). Figure 23 shows that the friction factor is reduced from that with normal stacking with this new stacking order. The reason is that there are fewer flow redistributions from 6-rib geometry to 7-rib geometry, or the reverse, with this stacking order.

\section{CFD Results (Cleveland State University)}

\section{A. CFD Introduction and Computational Models}

The Fluent CFD commercial code was used for 2-D and 3-D, steady and unsteady, fluid flow and heat transfer simulations of the segmented-involute-foil regenerator. The knowledge gained enabled fundamental understanding of how fluid flow and heat transfer takes place inside the segmented-involutefoil flow paths. It also helped provide support for physical testing (large-scale and actual-size); comparison of the micro-scale CFD results with the test results and Sage 1-D code simulations, provided additional insight for making decisions about the involute-foil design details.

It was decided early that it would not be feasible from a microscopic computational point of view to model the whole regenerator. Therefore it was necessary to look for simplifications which may be possible due to symmetries and boundary-condition approximations. One simplification comes from recognizing the periodicity in the radial direction that comes from the concentric arrangement of several rings of channels. The flow through the entire disk annulus can be approximated by the flow through just one ring of channels situated halfway between the OD and the ID of the annulus, as indicated in figure 24; this yields a seven-fold reduction in the computational domain. A further angular-direction-periodicity simplification comes from recognizing that there exists a sector of the ring of channels that, when repeated in the angular direction, reassembles the full ring. This is sometimes called circular symmetry. For the case studied the sector is about $8.87^{\circ}$, as indicated in figure 24 ; this reduces the domain by about 40 times (about 40 sectors make a full ring). If one chooses an area from the sector of figure 24 , and enlarges it - showing two layers with computational grids yields figure 25 . In figure 25 , one can see the channel walls, the angle formed between channel walls ( $81^{\circ}$ in this middle ring) in two successive layers

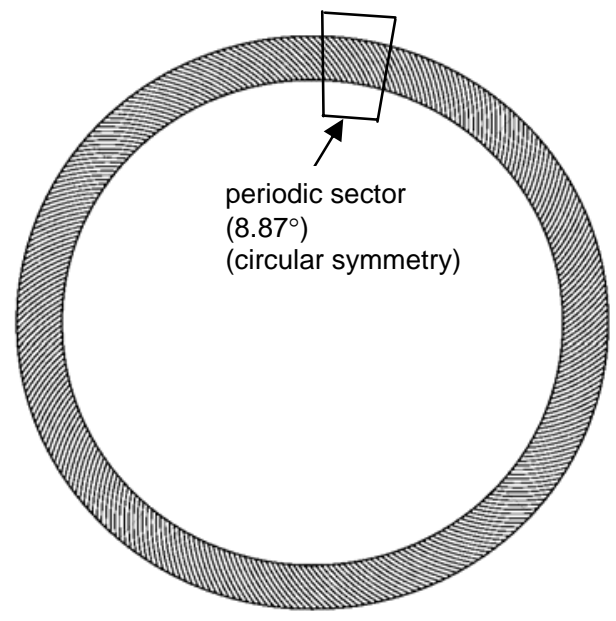

Figure 24.-Ring of segmented-involute-foil channels in the "radial middle" of a microfabricated disk annulus, and a sector of that ring. 


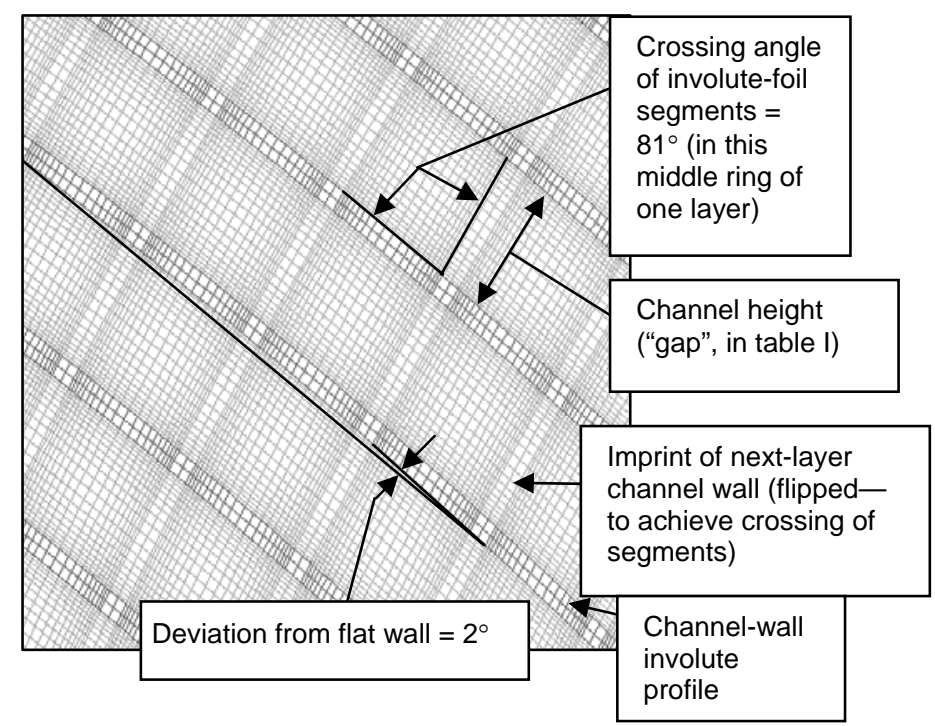

Figure 25.-Enlarged area from the middle of the periodic sector of figure 24 , showing portions of two layers of the disk annuli with computational grids. Some of these details will be simplified for straight-channel-layer simulations.

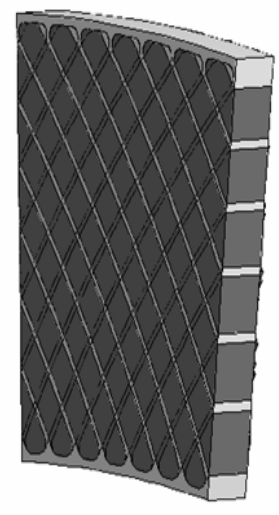

Half layer

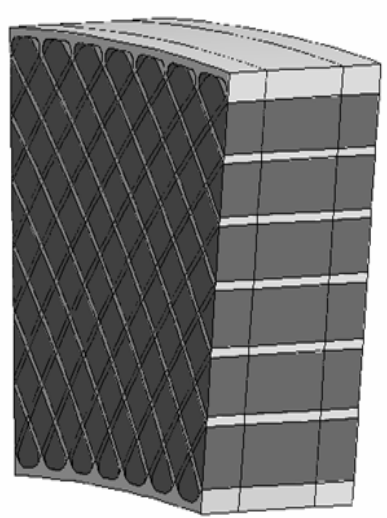

Repeating unit

Figure 26.-3-D involute-foil-layers computational domain, half-layer unit and repeating unit.

and how the involute-foil profile of the wall deviates from a flat wall (by about $2^{\circ}$ ). This suggests the further simplifications (approximations) of using straight walls and channels, in layers with walls that cross at a $90^{\circ}$ angle; this will be returned to later.

For steady-flow simulations, a further simplification comes from recognizing that the regenerator is a stack of just two types of alternating layers. Thus, the repeating unit is comprised of two layers. One can use the flow output of one repeating unit as the input to the next one, and so on. However, the interface between the two layers is a geometric discontinuity. The exit velocities and temperature profiles of one repeating unit would be used as inputs to the next. It is better to have no geometric discontinuities at inlets and outlets. Therefore, the selected repeating unit consisted of half the thickness of one layer, followed by a full-thickness layer, and ending in another half-thickness of the next layer. So a half-layer thickness was used at the inlet and exit, as shown in figure 26. 


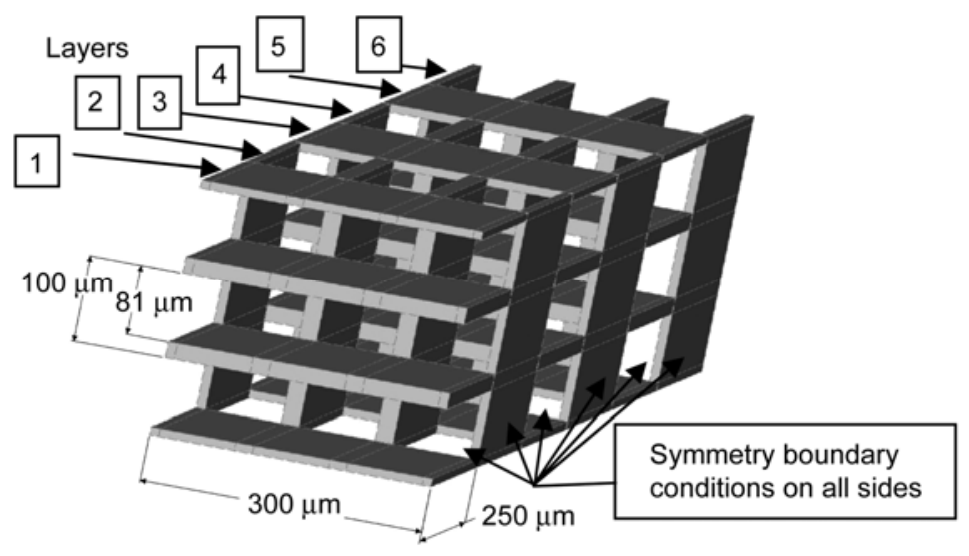

Figure 27.-3-D straight-channel-layers computational domain, 6 layers.

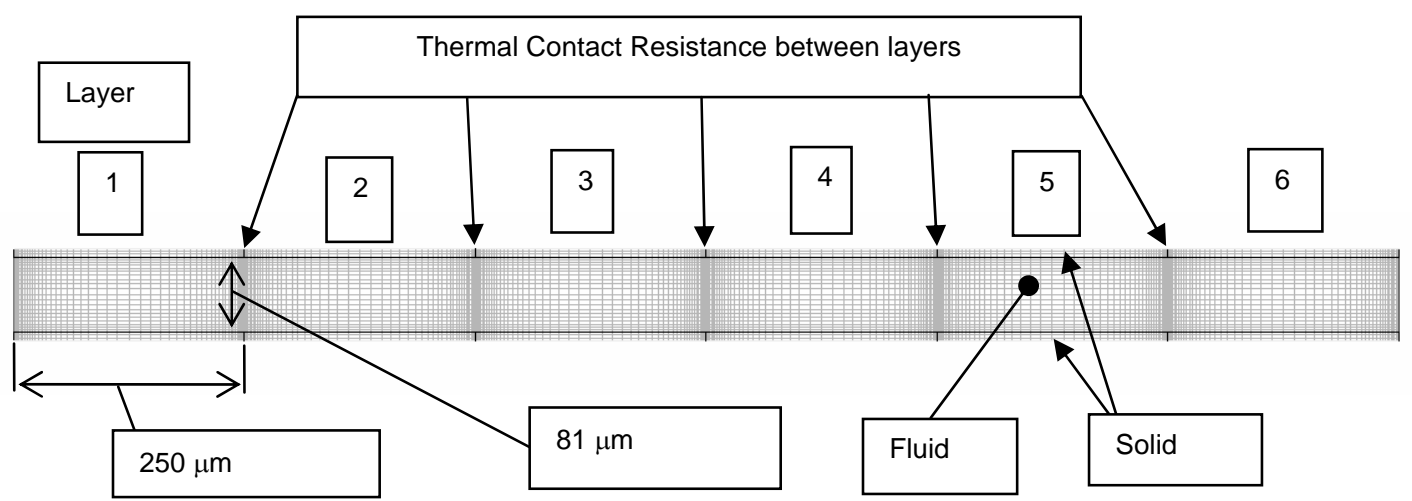

Figure 28.-2-D computational domain.

Flow-direction periodicity works only for steady-state modeling. The transient modeling of segmented foils requires oscillatory (alternating-direction, zero-mean) flow, requiring a stack of several layers to be included in the domain. A minimum of six layers was determined to be adequate to capture the oscillatory-flow phenomena. However even if radial and angular periodicities are employed, the grid size would still be too large for the available computation capability. Further simplifications, as indicated in figure 27 , must be used. If the foil-crossing angles of two adjacent layers are approximated by $90^{\circ}$ (instead of the $81^{\circ}$ shown in figure 27), the involute-foil profiles are approximated as straight, and the round ends of the channels are neglected - then one can build a manageable grid. These approximations, as indicated in figure 27, are expected to capture most of the 3-D oscillatory-flow phenomena of the segmented-involute-foil design.

Further simplifications were also made, for part of the CFD study, by using a 2-D computational domain. The 2-D domain consisted of a single parallel-plate channel with 6 successive sections, as shown in figure 28. There was no variation in flow geometry upon exiting one section and entering the next. However, by changing the solid-interface settings, one could set various values for the thermal contact resistance (TCR) between sections. This was expected to capture the interruption in the wall thermal conduction that is obtained by alternating the orientation of the channel walls (from one layer to the next) in the 3-D domain. This 2-D domain was used for grid-independence studies, quick parametric studies, and finding trends that could be later confirmed in 3-D with fewer runs. 


\section{B. Samples of the CFD Results}

The 2-D model of six layers shown in figure 28 was used in a grid-independence study to determine that 50 horizontal by 20 vertical grids per layer was sufficiently dense that further increases in grid density did not significantly affect the results. Various ratios of successive cell widths were also tried to make appropriate allowances for denser grids where velocity or temperature gradients were expected to be higher (near the walls and near the non-zero thermal contact resistances between layers). Good accuracy is particularly important where velocity and temperature gradients are large, since 2nd law (of thermodynamics) analysis shows that irreversible thermodynamic losses are sums of functions of the squares of these velocity and temperature gradients (ref. 13). The 2-D results were also used to calculate friction-factor and mean-Nusselt-number results for comparison with correlations from Shah (ref. 14) and Stephan (ref. 15), respectively, to validate the computations (see ref. 7 for more detailed results). Helium, stainless steel and nickel properties used in this CFD study are given in reference 7. For steady-state runs, the solid temperature was kept constant at $673 \mathrm{~K}$ while the fluid entered the channel at $660 \mathrm{~K}$. For the oscillatory-flow runs, base-case operating conditions are given in table II.

$\begin{array}{r}\text { TABLE II.-BASE CASE FOR OSCILLATORY-FLOW CONDITIONS } \\
\text { (USING HELIUM GAS AND STAINLESS-STEEL WALLS) }\end{array}$
\begin{tabular}{|l|l|}
\hline${\text { Valensi number, } \mathrm{Re}_{\omega}}$ & 0.22885 \\
\hline Maximum Reynolds number, $\mathrm{Re}_{\max }$ & 49.78 \\
\hline Frequency, $\mathrm{Hz}$ & 27.98 \\
\hline Hydraulic diameter, $\mathrm{m}$ & 0.000162 \\
\hline Max mass flux, $\mathrm{kg} / \mathrm{m}^{2}$-s & 6.17215 \\
\hline Cold end solid B.C. & Adiabatic \\
\hline Hot end solid B.C. & Adiabatic \\
\hline Inlet fluid temperature, cold end, K & 293.1 \\
\hline Inlet fluid temperature, hot end, K & 310.2 \\
\hline Mean pressure, Pa & 2500000 \\
\hline Mean, max velocity, $\mathrm{m} / \mathrm{s}$ & 1.5488 \\
\hline
\end{tabular}

For the oscillatory-flow simulations the base-case forcing function, at $27.98 \mathrm{~Hz}$, is:

$$
\text { Mass flux }=6.17215 * \cos (2 * \pi * 27.98 * \mathrm{t}+1.56556)\left(\mathrm{kg} / \mathrm{m}^{2}-\mathrm{s}\right)
$$

This function is applied at the west (left) fluid boundary (e.g., see fig. 28). By monitoring an oscillatory flow variable through several cycles, one notices that it takes several cycles until the monitored variable starts varying between the same minimum and maximum values. The final condition is called cycle-tocycle convergence, or is said to have converged to a steady-periodic cycle. All the following 2-D oscillatory-flow cases were run until cycle-to-cycle convergence was obtained and only after that were the data extracted. For the base case, it took approximately 10 cycles to obtain cycle-to-cycle convergence, based on monitoring temperature in the middle of layer three.

The friction factor obtained from the 2-D CFD oscillatory-flow results is compared with the experimental involute-foil correlation obtained by Gedeon from the NASA/Sunpower oscillating-flow rig test results (ref. 7) in figure 29; Darcy friction factors are plotted as functions of crank angle. The values obtained from the 2-D CFD simulation fall below the test-data correlation. This was expected since the correlation was obtained from experimental results from an actual involute-foil regenerator while the present 2-D simulation represents an idealized case, with flow through a foil (parallel-plate) channel that does not flow around foils in adjacent layers (i.e., there are no obstacles in the flow path).

In order to characterize the heat transfer that takes place during an oscillatory-flow run, the mean Nusselt number is plotted with respect to the crank angle in figure 30. For comparison, the experimental involute-foil correlation for the mean Nusselt number (ref. 7) is used (the correlation equation is also shown in figure 30). However, the test-data correlation represents a mean over the length of a stack of 42 layers, while the present work (the CFD results) focuses only on the region from the middle of layer 3 


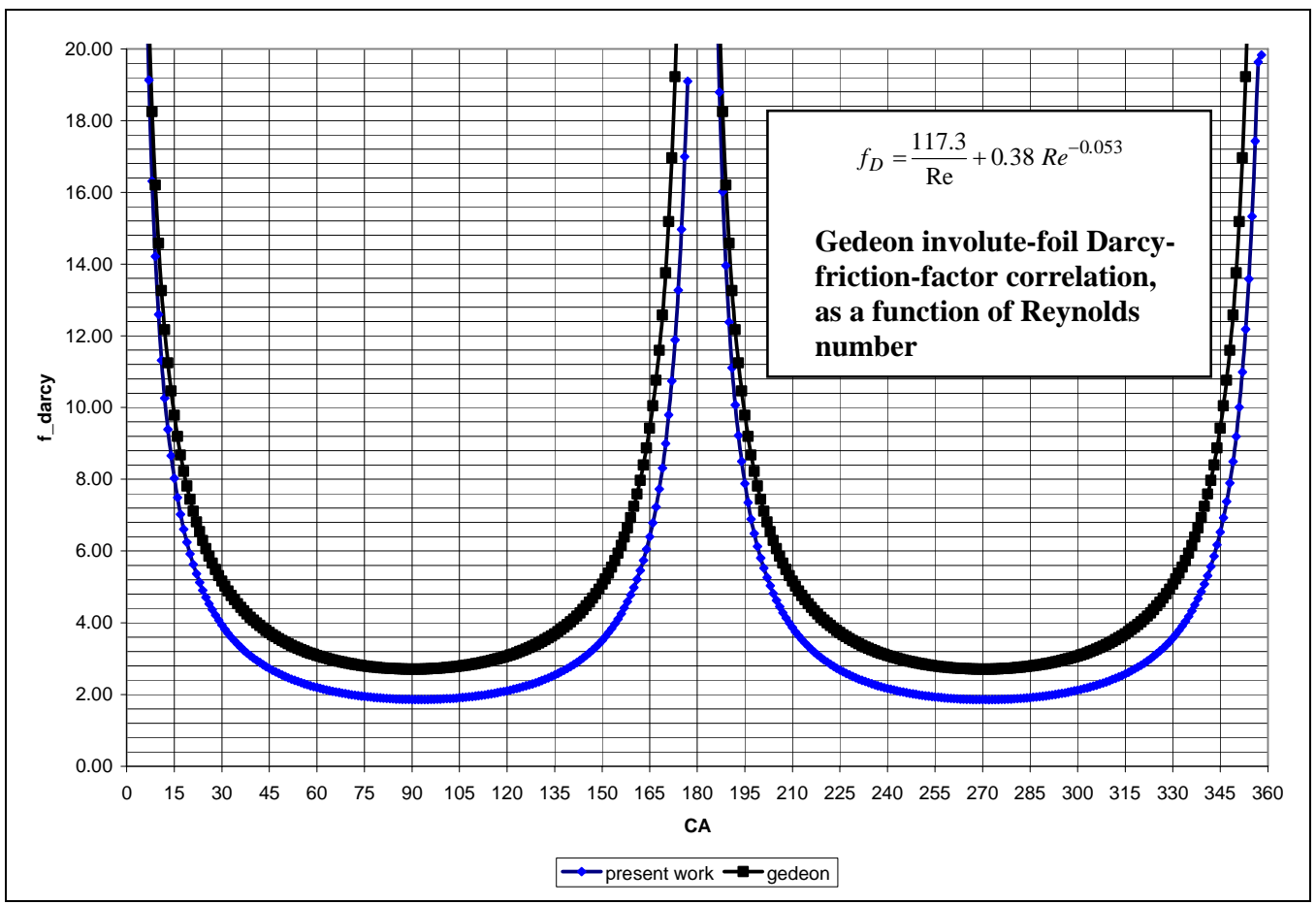

Figure 29._-Darcy friction factors, $f \_D a r c y$, as functions of crank angle, $C A$, degrees; comparisons of values calculated from 2-D CFD base-oscillatory-flow case ( 50 by 20 grids/segment) with Gedeon involute-foil test-data correlation; this test-data correlation is shown on the figure in the form of Darcy friction-factor as a function of Reynolds number.

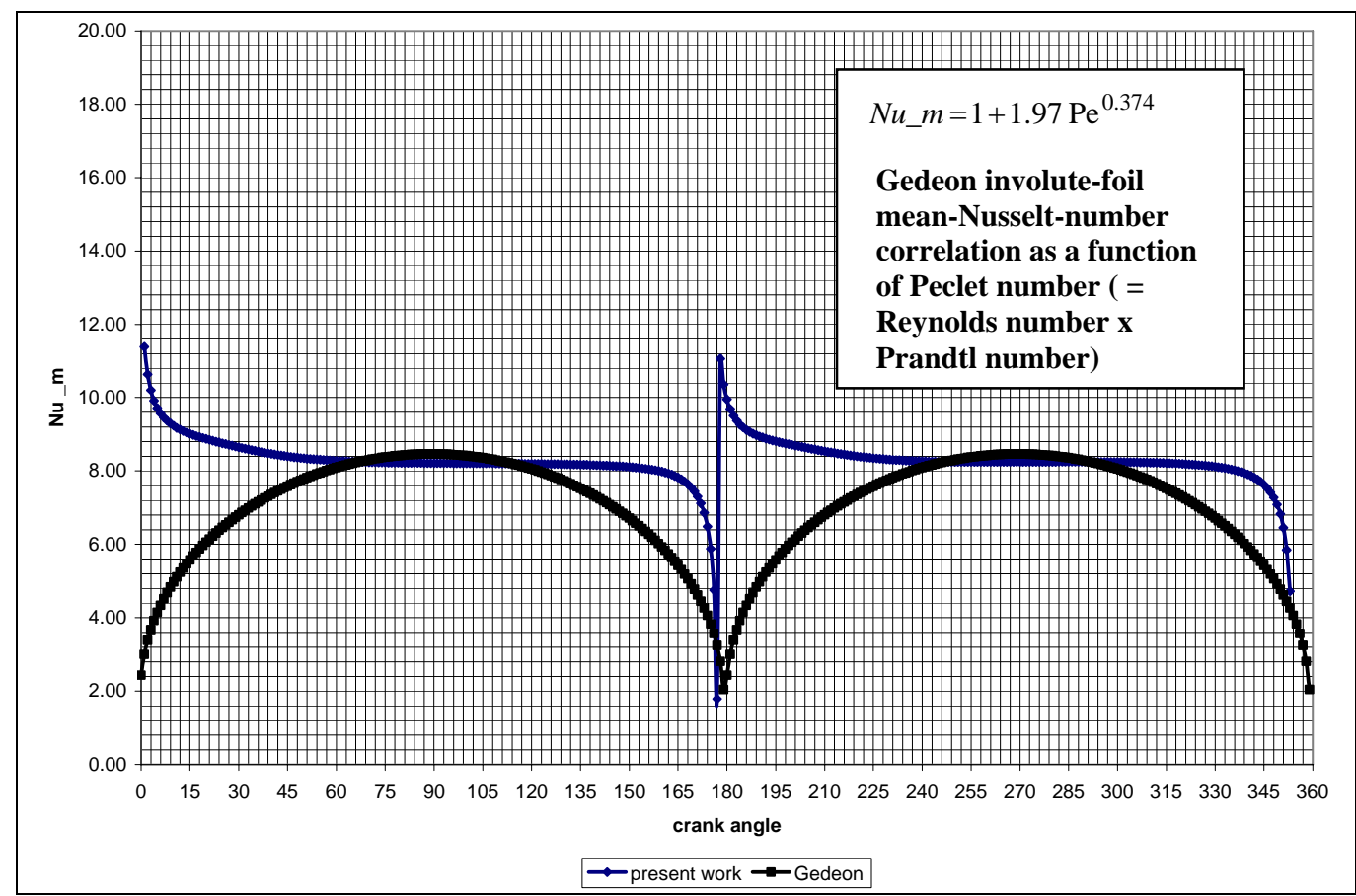

Figure 30.-Mean Nusselt numbers, $N u \_m$, as functions of crank angle, $C A$, degrees; comparison of values calculated from 2-D CFD base-oscillatory-flow case (50 by 20 grids/segment) with Gedeon involute-foil test-data correlation \{CFD assumes perfect thermal contact between layers, or zero thermal contact resistance (TCR)\}. 
to the middle of layer 4. So the length over which the Nusselt number is averaged in the present work is equal to the thickness of one layer only. That is done in order to stay away from the ends where entrance effects can distort the results. On the other hand, calculating a mean Nusselt number over the length of six layers would not have been representative of the actual geometry. Furthermore, experimental testing done at the University of Minnesota looked at the mean Nusselt number calculated between two layers similar to what has been done in the present work. So, the shape of the mean-Nusselt-number, or $N u \_m$, plot versus the crank angle is different from the Gedeon correlation and this difference arises from how the Nusselt number is averaged. The University of Minnesota experimental results show a Nusselt number curve similar to the present work. However, the comparison with the Gedeon correlation is useful for the maximum Reynolds number regions that are located around $90^{\circ}$ and $270^{\circ}$ crank angle, where flow rates are maximum in the two directions. At these locations, the 2-D analysis lies slightly below the correlation.

In figure 30, note the CFD results' significantly different characteristics for mean Nusselt number are near $180^{\circ}$ and $360^{\circ}$ crank angles, where flow accelerations and decelerations are greatest; the UMN experimental results show similar characteristics (refs. 7 and 10). These are due to phase-angle differences between the heat transfer at the wall and the temperature difference between the wall and mean-fluid temperature, which are used in calculating the Nusselt number; as mentioned above, these effects don't show up to the same degree in the NASA/Sunpower oscillating-flow rig results because those Nusselt number results are averaged over the entire 42-disk stack.

One goal of these 2-D oscillatory-flow cases was to determine the effect of various parameter changes on the axial heat losses (conduction and enthalpy flow losses). Table III summarizes these axial heat losses for the base-case 2-D oscillatory-flow run corresponding to the plots of figures 29 and 30 .

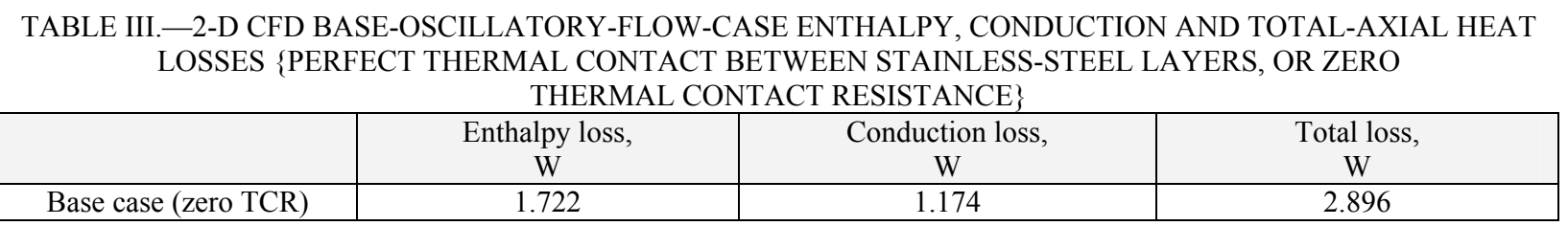

Suppose, instead of perfect contact (zero thermal contact resistance, or TCR), there was a very large or infinite TCR between layers. The effect on the axial heat losses determined by 2-D CFD oscillatoryflow simulation for a change from zero to infinite TCR is summarized in table IV. The table shows that there was a net 14 percent decrease in the total loss with this increase in TCR, although enthalpy loss actually increased by almost 14 percent.

TABLE IV.-AXIAL HEAT-LOSS COMPARISON OF ZERO-TCR BASE CASE TO INFINITE-TCR CASE (2-D OSCILLATORY-FLOW, STAINLESS-STEEL LAYERS)

\begin{tabular}{|l|c|c|c|c|c|c|}
\hline & $\begin{array}{c}\text { Enthalpy loss, } \\
\text { W }\end{array}$ & Change & $\begin{array}{c}\text { Conduction loss, } \\
\text { W }\end{array}$ & Change & $\begin{array}{c}\text { Total loss, } \\
\text { W }\end{array}$ & $\begin{array}{c}\text { Change } \\
\text { Base case (Zero TCR) }\end{array}$ \\
\hline Infinite TCR & 1.722 & & 1.174 & & 2.896 & \\
\hline
\end{tabular}

Since the prototype involute-foils were fabricated from nickel, instead of the originally planned and desired stainless steel, it was of interest to learn the impact of the higher conductivity nickel on axial heat losses. So a switch was made from stainless-steel layers with infinite TCR (2nd case in table IV) to nickel layers with infinite TCR. The effect of this change from stainless-steel to nickel, as simulated via 2-D CFD oscillatory-flow, is shown in table $\mathrm{V}$. The conduction loss increased by $\sim 36$ percent, but since the enthalpy loss was substantially larger and decreased by $\sim 5$ percent, the total axial heat loss increased by only about 4 percent. 
TABLE V.-AXIAL-HEAT-LOSS COMPARISON BETWEEN STAINLESS-STEEL AND NICKEL MATERIALS, BOTH WITH INFINITE TCR (OR ADIABATIC CONTACT) AT INTERFACES BETWEEN LAYERS \{BASED ON 2-D CFD OSCILLATORY-FLOW SIMULATIONS

\begin{tabular}{|l|c|c|c|c|c|c|}
\hline & $\begin{array}{c}\text { Enthalpy loss, } \\
\mathrm{W}\end{array}$ & Change & Conduction loss, W & Change & $\begin{array}{c}\text { Total loss, } \\
\mathrm{W}\end{array}$ & \begin{tabular}{c} 
Change \\
\hline $\begin{array}{l}\text { Infinite TCR } \\
\text { and stainless steel }\end{array}$
\end{tabular} \\
\hline $\begin{array}{l}\text { Infinite TCR } \\
\text { and nickel }\end{array}$ & 1.960 & & 0.531 & & 2.491 & \\
\hline
\end{tabular}

The 3-D steady-flow CFD simulations provide insight into the effects of the geometrical changes at the interfaces between the foil layers, which don't exist in the geometry of the 2-D simulations.

Figures 31 and 32 compare Darcy friction factors and mean Nusselt numbers determined from 2-D, 3-D straight-channel-layers and 3-D involute-foil-layers simulations, with test-data correlations.

In figure 31, for Reynolds number of 50, the 3-D involute-foil-layers simulation shows a variation in friction factor (the saw shape) similar to the 3-D straight-channel layers, as expected. One thing to keep in mind is that the length of the involute-foil layer is $15 \mu \mathrm{m}$ longer in the flow direction than the 3-D straight-channel layer. While work was in progress on this project it was learned that the actual fabricated layers were shorter than originally intended. The 3-D straight channel was adapted to the shorter length and simulations were performed that way. However, the 3-D involute-foil layer length simulated was kept at the original length. The above comparison captures this difference graphically by showing that the layer-to-layer rise in friction factor for the 3-D involute-foil layers happens after the rise shown by the 3-D straight-channel layers.

Figure 31 shows Darcy friction factors as functions of the dimensionless length, $\mathrm{x}+$. The Shah correlation (ref. 14) is below the 2-D simulation in the entry section, but then matches well with the 2-D simulation results as the flow becomes more fully developed at larger $\mathrm{x}^{+}$. The 3-D results agree well with the 2-D results for the first layer. Upon entering the second layer, the flow encounters a geometry change.

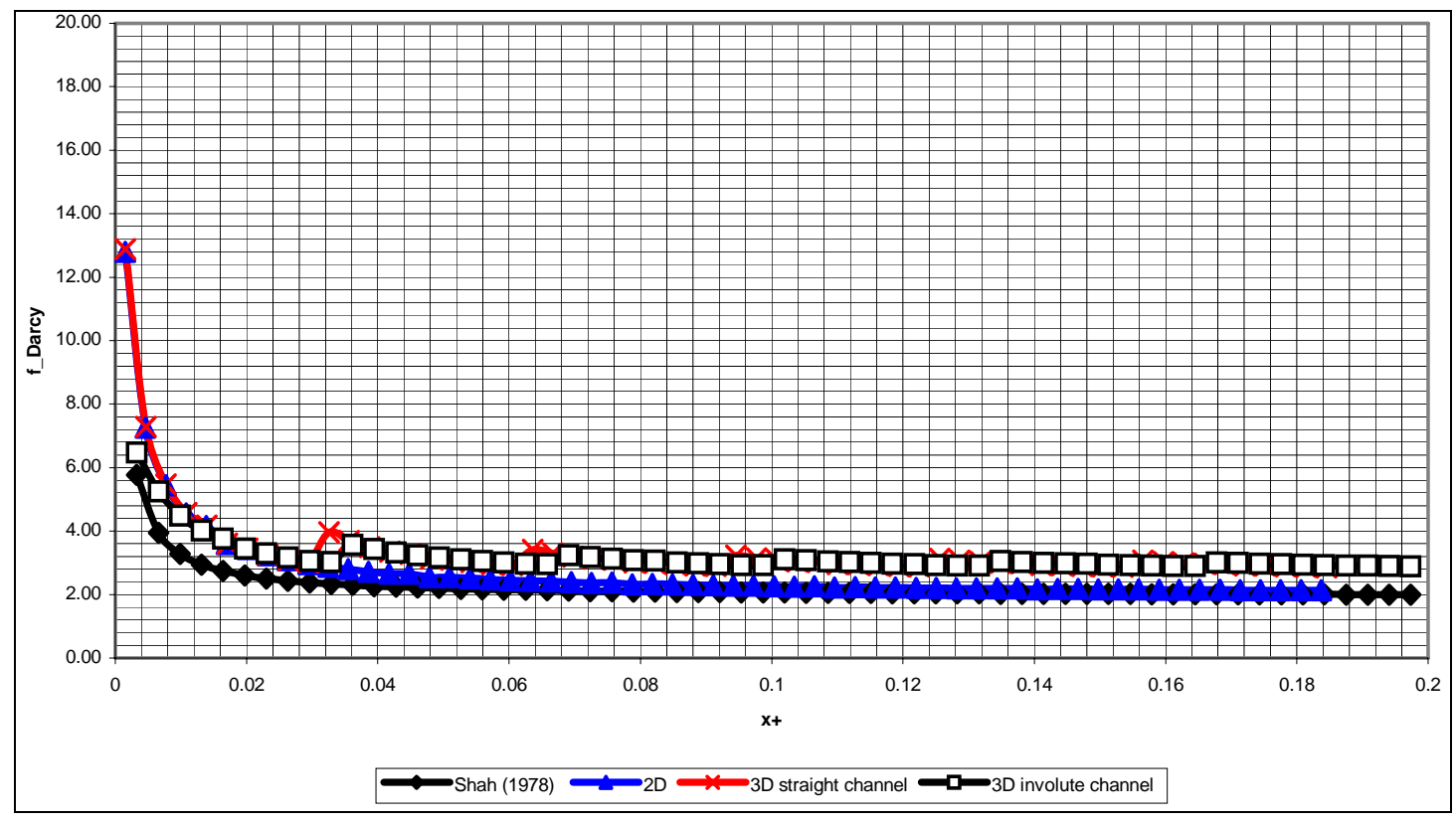

Figure 31.-Steady-state Darcy-friction-factor comparisons at Reynolds number, $R e=50$ as a function of dimensionless length, $x+$. Calculated via the 3-D involute-foil and straight-channel layer simulations, the 2-D parallel-plate simulation-and compared with the Shah correlation (ref. 14). 


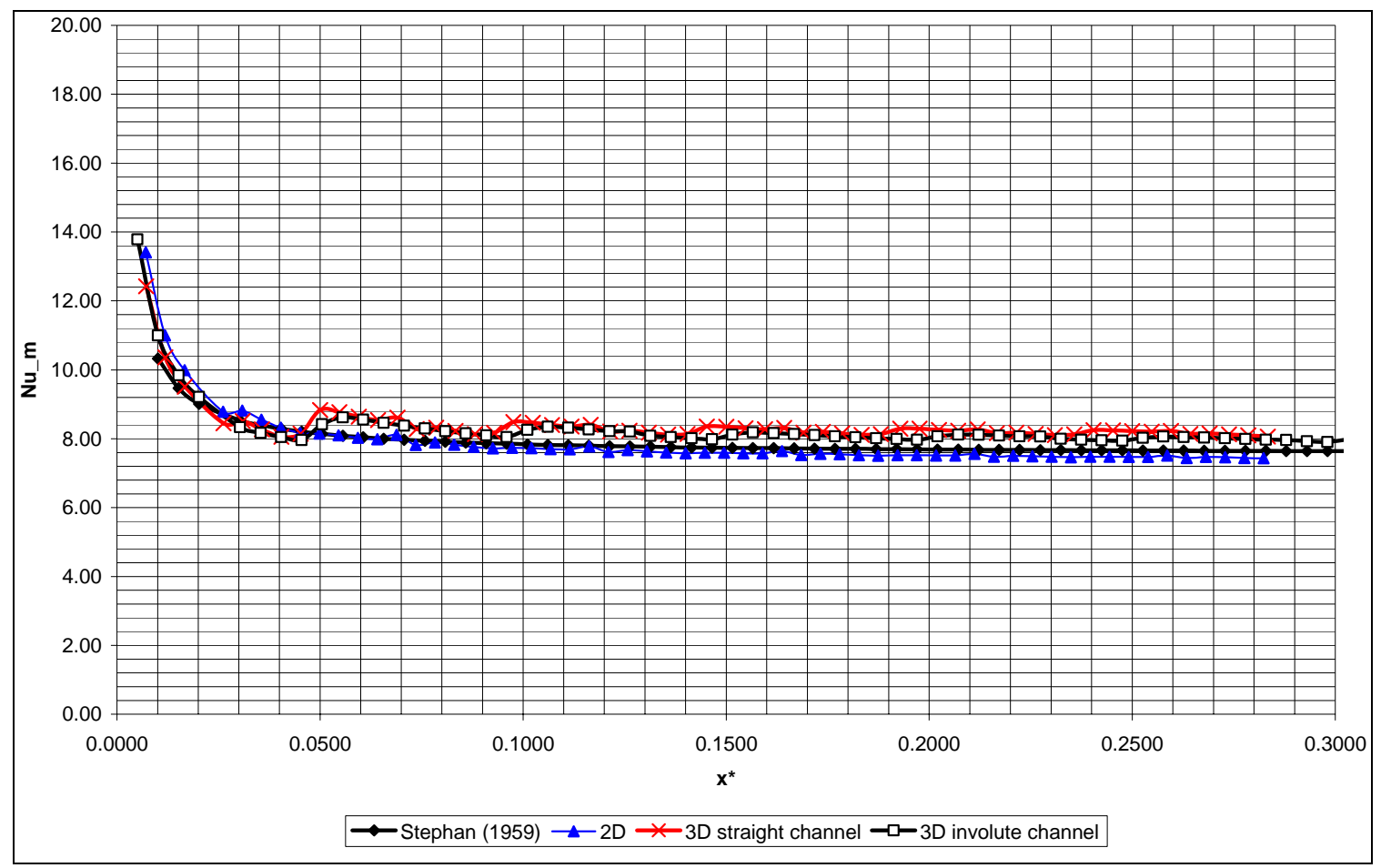

Figure 32.-Steady-state mean-Nusselt-number comparisons at Reynolds number, $\operatorname{Re}=50$ as a function of dimensionless length, $x^{*}$. Calculated via the 3-D involute-foil and straight-channel layer simulations, the 2-D parallel-plate simulation-and compared with the Stephan correlation (ref. 15).

That is where the friction factor goes up and departs from the agreement with the 2-D results. Then the flow tries to settle again until it encounters another geometry change upon entry into the third layer. As it moves through the stack of layers, the behavior of the fluid flow settles into periodicity, with small increases in friction factor upon entering each layer and with an average value above the 2-D prediction. This behavior was expected and the simulation provided an answer regarding the magnitude of the friction factor increase.

Figure 32 shows mean Nusselt numbers as functions of the thermal dimensionless length, $x^{*}$. The 3-D results agree well with the Stephan correlation (ref. 15) and the 2-D simulation for the first layer. However, the Nusselt number increases for the following layers. This is expected because of the disturbance in the thermal boundary layer introduced by the changing orientation of the channels. After several layers, the heat transfer settles into a periodic behavior with an average Nusselt number higher than the 2-D simulation and Stephan correlation (ref. 15).

\section{Structural Analysis (Infinia Corporation)}

This section reports on the regenerator structural analysis results which helped demonstrate the feasibility of the design. To ensure that the stiffness and the stress levels meet the design criteria, linear stress analysis was carried out. This section presents a brief summary of the results of a finite element analysis on four layers of the microfabricated, involute-foil regenerator under $44 \mathrm{~N}(10.0 \mathrm{lb})$ axial force (case 1) and $4.4 \mathrm{~N}(1.0 \mathrm{lb})$ radial-side-disturbance force acting on, first 0.047 percent of the top layer outside annular ring, and then on 10 percent of the top layer outside annular ring (cases 2 and 3 , respectively).

Without using symmetry or periodic-symmetry conditions, all $360^{\circ}$ of the geometry was included in the finite-element model shown schematically in figure 33. The thicknesses of the annular rings and the involute segments were much smaller than the other 2 dimensions. To allow the model to be handled by 


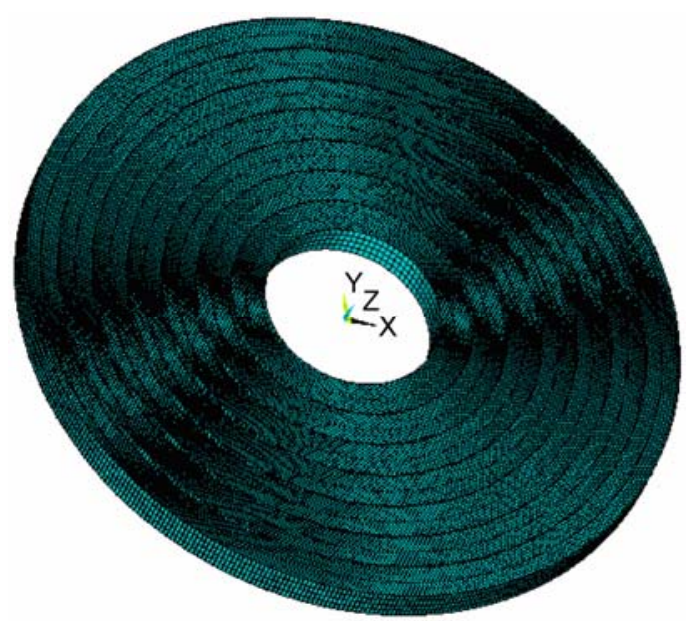

Figure 33.-Finite-element-analysis (FEA) model of four involute-foil layers.

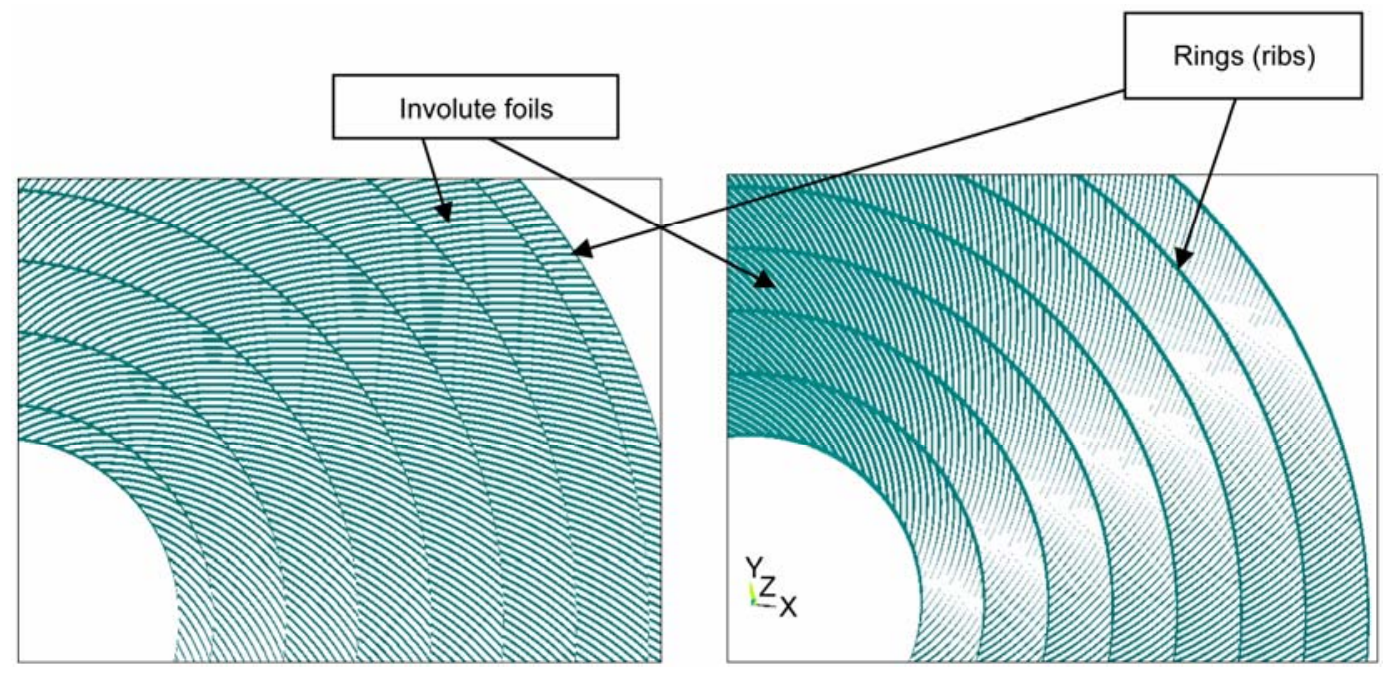

Figure 34.-Geometries of two different types of layers in finite-element-analysis (FEA) model.

the computer power available, the finite-element-analysis model was simplified as surfaces in 3-D space with four layers in the axial direction. ANSYS shell element shell63 was used in the FEA to reduce the size of the model. The regenerator was made from type $316 \mathrm{~L}$ stainless steel and the assumption was made that the material properties were not sensitive to temperature change.

The material properties of type $316 \mathrm{~L}$ stainless steel used in the FEA were: Young's modulus = $1.9 \times 10^{11} \mathrm{~N} / \mathrm{m}^{2}\left(2.796 \times 10^{7} \mathrm{psi}\right) ;$ Poisson's ratio $=0.3 ;$ Tensile strength $=4.97 \times 10^{8} \mathrm{~N} / \mathrm{m}^{2}\left(7.21 \times 10^{4} \mathrm{psi}\right)$; Yield strength $=1.8 \times 10^{8} \mathrm{~N} / \mathrm{m}^{2}\left(2.61 \times 10^{4} \mathrm{psi}\right)$. Other geometric dimensions used were: Thicknesses of the involute sections, inside annular rings, and the outside annular ring were $12.7 \mu \mathrm{m}(0.0005 \mathrm{in}$.); $25.4 \mu \mathrm{m}$ (0.001 in.), and $127 \mu \mathrm{m}\left(0.005 \mathrm{in}\right.$.), respectively. Total box volume was about $270 \mathrm{~mm}^{3}$ $\left(0.0165\right.$ in. $\left.^{3}\right)$; the mass volume was about $44.5 \mathrm{~mm}^{3}\left(0.0027163 \mathrm{in}^{3}\right)$; so, the porosity was about 84 percent. Individual disk thickness (axial direction) was $250 \mu \mathrm{m}$. The FEA was based on the preferred stainless-steel material, even though nickel was chosen for convenience in early testing of the performance of the involute-foil geometry.

For the four-layer FEA model shown in figure 33, there were two types of alternating layers as shown in figure 34 . 
The FEA maximum displacement and stress results for cases 1, 2, and 3 are summarized in table VI.

TABLE VI.-MAXIMUM DISPLACEMENT AND VON MISES STRESS FOR LOAD CASES 1, 2, AND 3

\begin{tabular}{|l|l|l|l|l|l|}
\hline \multicolumn{1}{|c|}{ Load case } & \multicolumn{1}{|c|}{$\begin{array}{c}\text { Disp. } U x \text { (in.) } \\
\text { \{plane of disk }\end{array}$} & $\begin{array}{c}\text { Disp. Uy (in.) } \\
\text { \{plane of disk }\end{array}$ & $\begin{array}{c}\text { Disp. Uz (in.) } \\
\text { \{axial\} }\end{array}$ & \multicolumn{1}{|c|}{ Total disp. (in.) } & $\begin{array}{c}\text { Von mises } \\
\text { stress (psi) }\end{array}$ \\
\hline Case 1 (axial force) & $0.734 \mathrm{e}-6$ & $0.736 \mathrm{e}-6$ & $0.646 \mathrm{e}-6$ & $0.804 \mathrm{e}-6$ & 1732 \\
\hline Case 2 (rad'l force 1) & $0.111 \mathrm{e}-3$ & $0.148 \mathrm{e}-3$ & $0.289 \mathrm{e}-5$ & $0.148 \mathrm{e}-3$ & 40624 \\
\hline Case 3 (rad'l force 2) & $0.462 \mathrm{e}-4$ & $0.304 \mathrm{e}-4$ & $0.735 \mathrm{e}-6$ & $0.462 \mathrm{e}-4$ & 6374 \\
\hline
\end{tabular}

Finite element analysis of the segmented-involute-foil regenerator shows that the regenerator had very high average axial direction stiffness $(3.75 \mathrm{e} 7 \mathrm{lb} / \mathrm{in}$.). Without any radial side disturbance, the stress level was much lower than the material yielding strength. If the radial side disturbance such as misalignment was localized in a small area, as in case 2, Von Mises stress was beyond the material yielding strength and permanent deformation could occur in that area, which may decrease the Stirling efficiency. In order to prevent local permanent deformation, the radial side load must be small or the disturbance area must be large, as in case 3.

In summary, the microfabricated segmented-involute-foil regenerator has high axial stiffness. The stress level is sensitive to radial side disturbance, which therefore requires special caution and appropriate processing during installation to prevent permanent lateral deformation.

\section{Phase II Conclusions, Phase III Plans, and Recommendations}

During Phase II an actual-size regenerator comprised of a stack of 42 disks, $19 \mathrm{~mm}$ in diameter and $0.25 \mathrm{~mm}$ thick (in the flow direction) - with microscopic involute-shaped flow channels - was microfabricated and tested in an oscillating-flow test rig. The geometry resembles an assembly of sections of uniformly spaced parallel plates, except that the plates are curved. The curved sections of plates, or involute foils, are incorporated in annular portions of the disks which are separated by concentric rings. Two types of disks alternate in the stack, so that the angles between the foils or plates in adjacent disks are close to $90^{\circ}$. Each disk was made from electroplated nickel using the LiGA (lithography, electroplating, forming) process. This process involved x-radiation of a photoresist through a mask, dissolving portions of the irradiated photoresist, then electroplating of nickel on a copper substrate within remaining photoresist channels, etc. This regenerator had feature sizes close to those required for an actual Stirling engine, but the overall regenerator dimensions were sized for the NASA/Sunpower oscillating-flow regenerator test rig. Examination by scanning electron microscope showed the disks were an accurate rendition of the design specification, except for a few flaws of types which are expected to be eliminated in the future via improvements to the manufacturing process (see reference 7 for more micrographs and discussion of these flaws). Testing in the NASA/Sunpower oscillating-flow test rig (refs. 1 to 4 ) showed the regenerator performed extremely well, producing the highest figures of merit ever recorded for any regenerator tested in this rig (since its fabrication about 20 years ago). Other regenerator materials recently tested in this rig include random-fiber, wire-screen and etched-foil materials.

Progress was also made in understanding the detailed fluid dynamics and heat transfer in the regenerator by CFD analysis at Cleveland State University and large-scale (30 times actual size) testing at the University of Minnesota. In general, the conclusions from the CFD and large-scale testing results reinforced those from the actual-size test results and revealed some important details about the microscopic flows responsible for the overall regenerator behavior.

A Phase III effort is now underway to microfabricate a stack of involute-foil disks to form a regenerator for testing in a modified Sunpower FTB engine. This engine was originally designed for a random-fiber regenerator and will not be reoptimized for the new involtue-foil regenerator-though some modifications will be made to the engine to accommodate the new regenerator and its lower pressure drop. The Phase III effort includes testing of this involute-foil equipped FTB (with hot-end temperature of $\left.650{ }^{\circ} \mathrm{C}\right)$. 
Beyond this Phase III effort, the microfabrication process needs to be further developed to permit microfabrication of higher temperature materials than nickel (pure nickel is too soft a material for practical use even in the $650{ }^{\circ} \mathrm{C}$ FTB engine; e.g., attempts to remove the nickel regenerator from an engine, once installed, would likely produce serious structural damage to the regenerator $\left.{ }^{*}\right)$. For examples of higher-temperature applications-NASA and Sunpower are currently developing an $850{ }^{\circ} \mathrm{C}$ engine for space-power applications. And, a potential power/cooling system for Venus applications would need regenerator materials capable of $\sim 1200^{\circ} \mathrm{C}$. Early Mezzo attempts to "EDM" stainless-steel using a LiGAdeveloped EDM tool involved a burn time (dependent on EDM machine setting) that was much too large to be practical. Some possible options for further development of a microfabrication process for hightemperature involute-foils are: (1) Optimization of an EDM process for high temperature materials, that cannot be processed by LiGA only; burn times can be greatly reduced by higher-power-EDM-machine settings than originally used, in Phase I, by Mezzo; but overburn, i.e., the gaps between the EDM tool and the resulting involute-foil channels, increases with higher powers (ref. 7); (2) development of a LiGA only process for some high temperature alloy, or pure metal, that would be appropriate for the regenerator application (pure platinum would work but has very high conductivity, which would tend to cause larger axial regenerator losses, and is very expensive), or (3) microfabrication of an appropriate ceramic material for high-temperature regenerators (structural properties of ceramics, which tend to be brittle, would be a concern).

\section{References}

1. Wood, J.G., Miller, E.L., Gedeon, D.R., and Koester, G.E. "Description of an Oscillating Flow Pressure Drop Test Rig,” NASA Technical Memorandum 100905, 1988.

2. Koester, G., Howell, S., Wood, G., Miller, E., and Gedeon, D. "Oscillating Flow Loss Test Results in Stirling Engine Heat Exchangers,” NASA Contractor Report 182288, 1990.

3. Gedeon, D. and Wood, J.G. "Oscillating-Flow Regenerator Test Rig: Woven Screen and Metal Felt Results,” NASA Contractor Report 190689, 1992.

4. Gedeon, D. and Wood, J.G. "Oscillating-Flow Regenerator Test Rig: Hardware and Theory with Derived Correlations for Screens and Felts,” NASA Contractor Report 198442, 1996.

5. Gedeon, D., Sage Stirling-Cycle Model-Class Reference Guide and User's Guide,, version 4 ed., Gedeon Associates, 16922 South Canaan Road, Athens, OH, April 12, 2006.

6. Ibrahim, M., Simon, T., Mantell, S., Gedeon, D., Qiu, S., Wood, G., and Guidry, D., "Developing the Next Generation Stirling Engine Regenerator: Designing for Application of Microfabrication Techniques and for Enhanced Reliability and Performance in Space Applications," Cleveland State University, Radioisotope Power Conversion Technology NRA Contract No. NAS3-03124 Phase I Final Report, Prepared for NASA Glenn Research Center, Cleveland, OH, September 2004. This document is under consideration for publication as a NASA Contractor Report.

7. Ibrahim, M., Simon, T., Mantell, S., Gedeon, D., Qiu, S., Wood, G., Kelly, K. and McLean, J., "Developing the Next Generation Stirling Engine Regenerator: Designing for Application of Microfabrication Techniques and for Enhanced Reliability and Performance in Space Applications," Cleveland State University, Radioisotope Power Conversion Technology NRA Contract No. NAS303124 Phase II Final Report, Prepared for NASA Glenn Research Center, Cleveland, OH, January 2007. Also being prepared for publication as a NASA Contractor Report under the name, "A Microfabricated Segmented-Involute-Foil Regenerator for Enhancing Reliability and Performance of Stirling Engines, publication expected in 2007 NASA/CR-2007-215006.

8. Sun, L., Mantell, S.C., Gedeon, D. and Simon, T.W. "A Survey of Microfabrication Techniques for Use in Stirling Engine Regenerators,” Paper No. AIAA-2004-5647, Proceedings of the 2nd International Energy Conversion Engineering Conference, Providence, RI, 2004.

\footnotetext{
*An opinion expressed by Gary Wood, Stirling engine designer at Sunpower.
} 
9. Rulich, I. and Quack, H. "Investigations on Regenerative Heat Exchangers," Cryocoolers 10 Conference Proceedings, edited by R. G. Ross, Jr., Klewer Academic/Plenum Publishers, pp. 265274, 1999.

10. Sun, L., Simon, T.W., Mantell, S.C., Gedeon, D., Ibrahim, M.B. and Tew, R., "Thermo-fluid Experiments Supporting Microfabricated Regenerator Development for a Stirling Space Power Engine," In preparation for submission to the AIAA Journal of Propulsion and Power.

11. Seume, J.R., Friedman, G., and Simon, T.W. "Fluid Mechanics Experiments in Oscillating Flow Volume I-Report," NASA Contractor Report 189127, 1992.

12. Kays, W., and London, A., Compact Heat Exchangers, 3rd ed., McGraw-Hill, Inc., 1984.

13. Ebiana, A.B., Savadekar, R.T., and Patel, K.V. "Entropy Generation/Availability Energy Loss Analysis inside MIT Gas Spring and 'Two-Space' Test Rigs," NASA/CR—2006-214339, 2006.

14. Shah, R.K., "A correlation for laminar hydrodynamic entry length solutions for circular and noncircular ducts," Journal of Fluids Eng., 100, 1978, pp. 177-179.

15. Stephan, K, "Warmeubergang und druckabfall bei nicht ausgebildeter Laminarstromung in Rohren und in ebenen Spalten," Chem.-Ing.-Tech., 31, 1959, pp. 773-778. 


\begin{tabular}{|c|c|c|c|c|c|}
\hline \multicolumn{5}{|c|}{ REPORT DOCUMENTATION PAGE } & $\begin{array}{l}\text { Form Approved } \\
\text { OMB No. 0704-0188 }\end{array}$ \\
\hline \multicolumn{6}{|c|}{ 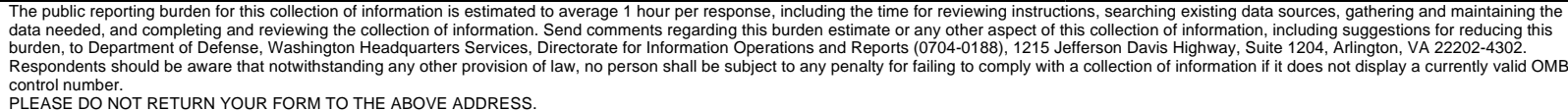 } \\
\hline \multicolumn{2}{|c|}{$\begin{array}{l}\text { 1. REPORT DATE (DD-MM-YYYY) } \\
01-10-2007\end{array}$} & \multicolumn{3}{|c|}{$\begin{array}{l}\text { 2. REPORT TYPE } \\
\text { Technical Memorandum }\end{array}$} & 3. DATES COVERED (From - To) \\
\hline \multirow{3}{*}{\multicolumn{5}{|c|}{$\begin{array}{l}\text { 4. TITLE AND SUBTITLE } \\
\text { A Microfabricated Involute-Foil Regenerator for Stirling Engines }\end{array}$}} & 5a. CONTRACT NUMBER \\
\hline & & & & & 5b. GRANT NUMBER \\
\hline & & & & & 5c. PROGRAM ELEMENT NUMBER \\
\hline \multirow{3}{*}{\multicolumn{5}{|c|}{$\begin{array}{l}\text { 6. AUTHOR(S) } \\
\text { Tew, Roy; Ibrahim, Mounir; Danila, Daniel; Simon, Terrence; Mantell, Susan; Sun, Liyong; } \\
\text { Gedeon, David; Kelly, Kevin; McLean, Jeffrey; Wood, Gary; Qiu, Songgang }\end{array}$}} & 5d. PROJECT NUMBER \\
\hline & & & & & 5e. TASK NUMBER \\
\hline & & & & & $\begin{array}{l}\text { 5f. WORK UNIT NUMBER } \\
\text { WBS 138494.04.01.01 }\end{array}$ \\
\hline \multicolumn{5}{|c|}{$\begin{array}{l}\text { 7. PERFORMING ORGANIZATION NAME(S) AND ADDRESS(ES) } \\
\text { National Aeronautics and Space Administration } \\
\text { John H. Glenn Research Center at Lewis Field } \\
\text { Cleveland, Ohio 44135-3191 }\end{array}$} & $\begin{array}{l}\text { 8. PERFORMING ORGANIZATION } \\
\text { REPORT NUMBER } \\
\text { E-16146 }\end{array}$ \\
\hline \multirow{2}{*}{\multicolumn{5}{|c|}{$\begin{array}{l}\text { 9. SPONSORING/MONITORING AGENCY NAME(S) AND ADDRESS(ES) } \\
\text { National Aeronautics and Space Administration } \\
\text { Washington, DC 20546-0001 }\end{array}$}} & $\begin{array}{l}\text { 10. SPONSORING/MONITORS } \\
\text { ACRONYM(S) } \\
\text { NASA }\end{array}$ \\
\hline & & & & & $\begin{array}{l}\text { 11. SPONSORING/MONITORING } \\
\text { REPORT NUMBER } \\
\text { NASA/TM-2007-214973; AIAA-2007- } \\
4739\end{array}$ \\
\hline \multicolumn{6}{|c|}{$\begin{array}{l}\text { 12. DISTRIBUTION/AVAILABILITY STATEMENT } \\
\text { Unclassified-Unlimited } \\
\text { Subject Category: } 20 \\
\text { Available electronically at http://gltrs.grc.nasa.gov } \\
\text { This publication is available from the NASA Center for AeroSpace Information, 301-621-0390 }\end{array}$} \\
\hline \multicolumn{6}{|c|}{ 13. SUPPLEMENTARY NOTES } \\
\hline \multicolumn{6}{|c|}{ 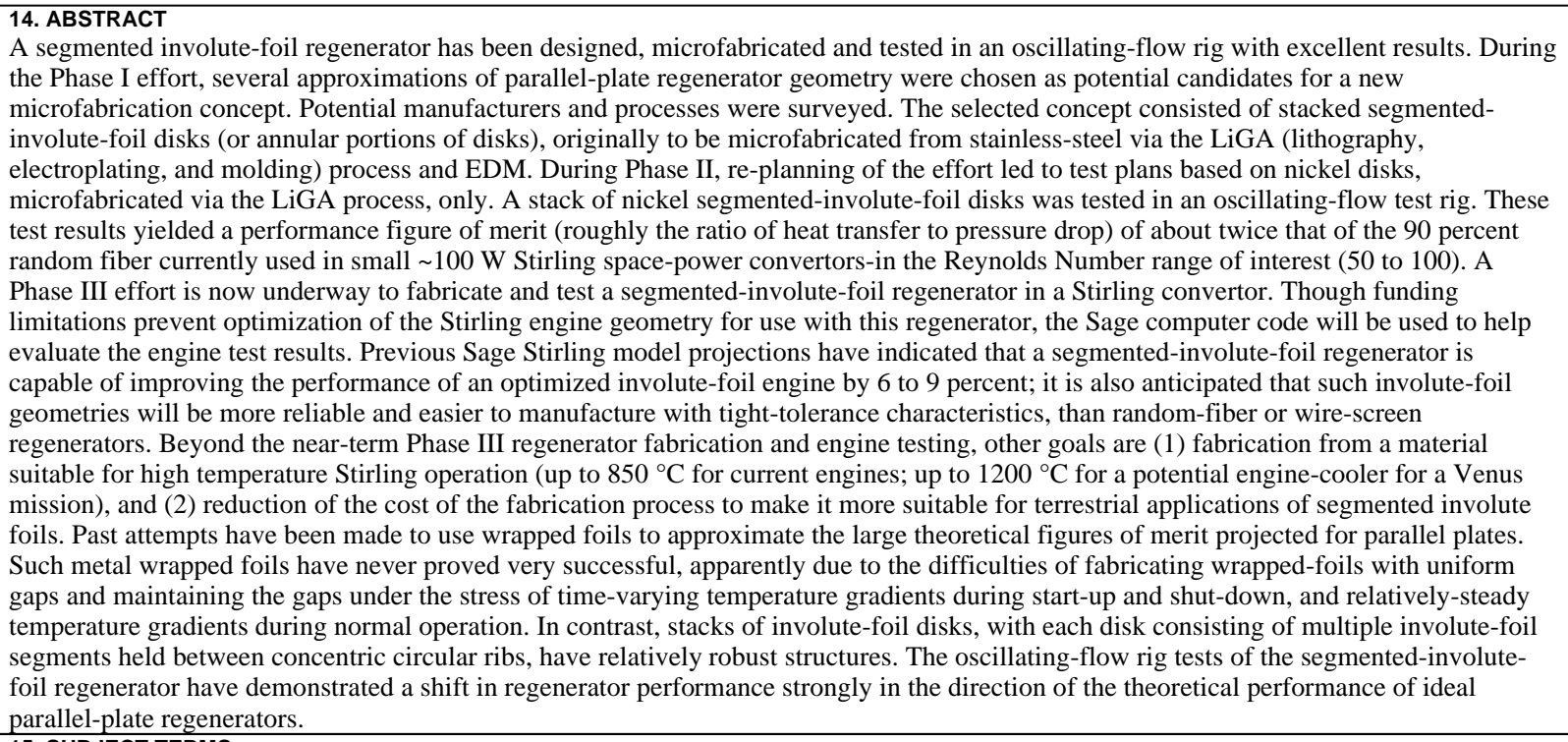 } \\
\hline \multicolumn{6}{|c|}{$\begin{array}{l}\text { 15. SUBJECT TERMS } \\
\text { Stirling; Involute-foil regenerator }\end{array}$} \\
\hline \multicolumn{3}{|c|}{ 16. SECURITY CLASSIFICATION OF: } & $\begin{array}{l}\text { 17. LIMITATION OF } \\
\text { ABSTRACT }\end{array}$ & $\begin{array}{l}\text { 18. NUMBER } \\
\text { OF }\end{array}$ & $\begin{array}{l}\text { 19a. NAME OF RESPONSIBLE PERSON } \\
\text { STI Help Desk (email:help@sti.nasa.gov) }\end{array}$ \\
\hline $\begin{array}{l}\text { a. REPORT } \\
\text { U }\end{array}$ & $\begin{array}{l}\text { b. ABSTRACT } \\
\text { U }\end{array}$ & $\begin{array}{l}\text { c. THIS } \\
\text { PAGE } \\
\text { U }\end{array}$ & UU & $\begin{array}{l}\text { PAGES } \\
36\end{array}$ & $\begin{array}{l}\text { 19b. TELEPHONE NUMBER (include area code) } \\
\text { 301-621-0390 }\end{array}$ \\
\hline
\end{tabular}



